

\title{
ELASTIC SCATTERING OF TRITONS BY HELIUM-4
}

\author{
by \\ Nelson Jarmie, F. D. Correll, Ronald E. Brown, \\ R. A. Hardekopf, and G. G. Ohisen
}

\begin{abstract}
Angular distributions of the differential cross section and of the analyzing power have been measured for the ${ }^{4} \mathrm{He}(\mathrm{t}, \mathrm{t})^{4} \mathrm{He}$ reaction at 19 energies from 6 to $17 \mathrm{MeV}$. The relative errors of the cross section and analyzing power range from 2.0 to $2.5 \%$ and 0.005 to 0.01 , respectively, and the scale errors are $1 \%$ in each case. Complete data tables are presented, and the experimental procedure is described for the present measurements and for earlier cross-section measurements. Graphs of the data are presented, as well as the curves resulting from an energy-independent phase-shift analysis.
\end{abstract}

\section{INTRODUCTION}

The elastic scattering of tritons by ${ }^{4} \mathrm{He}$ is important in studying the physics of the mass-7 nuclear system and in determining the parameters of the ${ }^{6} \mathrm{Li}(\mathrm{n}, \mathrm{t})^{4} \mathrm{He}$ reaction, a primary standard for neutron flux measurements. ${ }^{1} \mathrm{Com}$ parisons of the ${ }^{4} \mathrm{He}(\mathrm{t}, \mathrm{t})^{4} \mathrm{He}$ data may be made with predictions of the Resonating Group Method ${ }^{2}$ (RGM) and of an R-Matrix analysis. ${ }^{3}$ The experimental data of Spiger and Tombrello ${ }^{4}$ have been used to establish the energy level scheme oi ${ }^{1} \mathrm{Li}$ (Fig. 1) from about 4 to about $10 \mathrm{MeV}$ of excitation. We have increased our knowledge of this system by measuring analyzing powers, as well as additional and more accurate differential cross sections. Nineteen angular distributions were measured for triton beam energies from 6 to $17 \mathrm{MeV}$. Some earlier data have been reported in Los Alamos Scientific Laboratory (LASL) report LA-6188, ${ }^{5}$ and some of the present work was included in a preliminary report. ${ }^{6}$ The present data, which include the bulk of the analyzing power measurements, were measured with the apparatus described below.

\section{EXPERIMENTAL APPARATUS}

The experiment was performed at the LASL Van de Graaff facility and made use of the FN tandem Van de Graaff accelerator and the Lamb-shift polarized triton source. ${ }^{6.7}$ The scattering chamber used was a $61-\mathrm{cm}$ cube called the "supercube." References 5 and 6 describe the polarized triton source and the method of extracting analyzing powers. Additional experimental information is given in Ref. 9. The "He target gas was contained in a $9.7-\mathrm{cm}$-diam cell with a ceam-entrance snout about $6-\mathrm{cm}$ long. A $2.5-\mu \mathrm{m}$-thick Havar* foil covered the 2.5 -mm-diam beam-entrance aperture on the snout, and a 7 - $\mu \mathrm{m}$-thick Kapton ${ }^{* *}$ foil covered the $300^{\circ}$ cell opening through which the beam and detected particles emerged. This gas target was operated at room temperature and in a pressure range of 250-310 torr; the gas purity was better than $99.5 \%$. The target tem-

"Havar is the trade name for a cobalt "superalloy" manufactured by Hamilton Technology, Inc., Lancasier, Penn.

- Kapton is a polyimide film made by E.I. Du Pont de Nemours a Co., Washington, Del. 


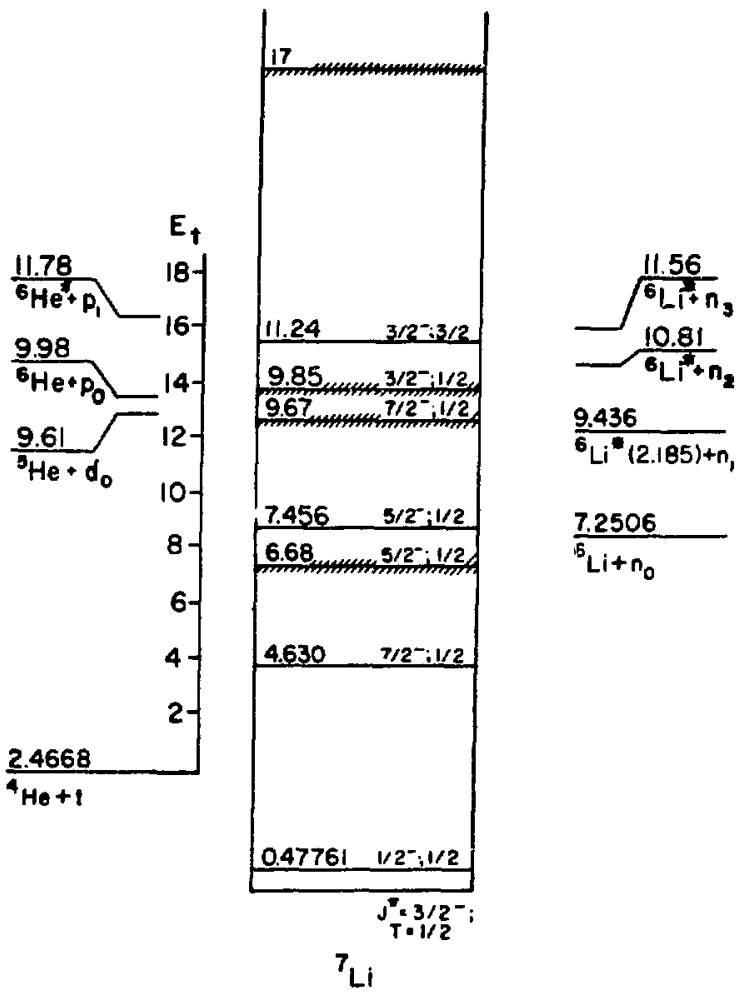

Fig. 1.

Energy level diagram from Ref. 19. The energies are in $\mathrm{MeV}$. There is possibly a very broad $3 / 2^{+}, 1 / 2$ level at 9.5 $\mathrm{MeV}$ (12.33 MeV $\mathrm{E}_{1}$ ).

perature was measured with a thermocouple attached to the cell. The target pressure was measured with a capacitance manometer whose digital read-out could be transmitted to an on-line computer.

Each of two detector assemblies, left and right of the beam direction, consisted of a stack of three silicon surface-barrier detectors mounted behind a standard gas-target collimator arrangement, which had a geometry factor $G_{00}$ of $7.0 \times 10^{5} \mathrm{~cm} \cdot \mathrm{sr}$ and an angular acceptance if $1 / 2^{\circ}$ to $1^{\circ}$ full width at half-maximum (FWHM). The relative and scale errors of the center of mass scattering angle are $0.05^{\circ}$ and $0.1^{\circ}$, respectively. The nominal thicknesses of the detectors in a stack were 17,150 , and $1500 \mu \mathrm{m}$ from front to back. We used the 17. and $150-\mu \mathrm{m}$ detectors to perform $\triangle \mathrm{E}-\mathrm{E}$ mass identification of the $a$-particles and simultaneously used the 150 - and $1500-\mu \mathrm{m}$ detectors to identify the tritons. The electronic circuitry was approximately as shown in Fig. 3 of Ref. 9. The polarized beam used had intensities up to $100 \mathrm{nA}$ and polarizations in the range 0.75 to 0.85 .
On-line data processing and control of some of the supercube and ion-source functions were carried out with an SDS-930 computer.

\section{ERROR ANALYSIS}

\section{A. Beam Energy}

The estimated uncertainties in the above-quoted beam energies include a scale error arising from the absolute calibration of the beam analyzing magnet and relacive errors stemming from nonlinearity of the analyzing magnet and uncertainties in the calcuiated beam-energy losses in the target.

The tandem Van de Graaff energy calibration is based on a measurement of the ${ }^{12} \mathrm{C}(\mathrm{p}, \mathrm{p})^{12} \mathrm{C}$ isospin-forbidden resonance at $14.23075 \pm 0.00020 \mathrm{MeV} .{ }^{10} \mathrm{We}$ believe the scale error in the calibration of the analyzing magnet from this measurement to be not more than $\pm 1 \mathrm{keV}$. The relative calibration error arising from nonlinearities in the analyzing magnet and from magnet-recycling and slit-setting procedures has not been studied completely. However, we estimate this error to be at most $\pm 3 \mathrm{keV}^{\prime}$ The uncertainty in the energy-loss calculations for tritons entering the gas cell is about $\pm 2 \mathrm{keV}$. The uncertainty in the thickness of the Havar entrance foil on the gas cell contributes an additional relative error of $\pm 11 \mathrm{keV}$. A quadratic sum of all these relative errors gives an overail energy uncertainty of $\pm 12 \mathrm{keV}$.

The energy spread of the incident beam at the target is dominated by straggling in the Havar entrance foil and the target gas in the cell. Calculations with the code STRAGL ${ }^{11}$ give mean straggling widths of $29 \mathrm{keV}$ in the Havar foil and $16 \mathrm{keV}$ in the ${ }^{3} \mathrm{He}$ target gas. The variation in these values is less than $\pm 1 \mathrm{keV}$ over the triton energy range. When the Havar and gas straggling widths are folded quadratically with the estimated $\pm 4-\mathrm{keV}$ terminal ripple of the Van de Graaff, the total energy spread in the incident beam is calculated to be $33 \mathrm{keV}$ FWHM.

\section{B. Analyzing Power}

The relative errors in the analyzing power $A_{y}$ arise from (1) counting statistics, including the background; (2) the method used to suburact the background; (3) random fluctuations in the measurement of the beam polanzation by the quench-ratio method; ${ }^{12}$ and (4) other 
random contributions, such as position instability in the beam. The errors shown in Table B-I are relative errors and are obtained by quadratically combining the counting statistics error with 0.005 , which we believe to be a reasonable estimate of the errors caused by the other factors mentioned above. This value for the random systematic error is based on experience with repeatability of data for this type of experiment.

The scale error for $A_{y}$ arises solely from vorious errors in determining the absolute value of the beam polarization using the quench-ratio technique because all other scale errors cancel for dat $s$ taken with symmetric geometry. ${ }^{13}$ The sources of scale error include

(1) the presence of an unpolarized, negatively charged background in the incident beam that masquerades as a polarized beam when electric, rather than magnetic, fields are used for quenching

(2) enhancement of the polarization by slit-edge scraping as the beam goes from the analyzing-magnet Faraday cup (where the quench ratio is measured) to the target; ${ }^{12,14}$

(3) the small, negative polarization in the quenched beam; ${ }^{12}$ and

(4) depolarization caused by residual gas in the terminal of the tandem Van de Graaff. ${ }^{15}$

In checking the effect of (1) periodically during the experiment, we discovered that the discrepancies between electric- and magnetic-field quench ratios were typically $0.010-0.015$ with infrequent excursions to as much as 0.025 . Polarization enhancement caused by beam scraping is believed to contribute no more than a 0.01 scale error. The error caused by small, negative polarization is probably on the order of 0.005 (Ref. 14). Both polarization enhancement and the small, negative polarization in the quenched beam tend to compensate for the error caused by (1). Terminal depolarization reduces the vector polarization by no more than 0.001 (Ref. 15). We estimate that all these effects cause a scale error of \pm 0.01 times $A_{y}(1 \%)$ in our $A_{y}$ measurements. This number is substantiated by the results of Ref. 6 .

At the larger scattering angles of the recoil ${ }^{4} \mathrm{He}$ particles, multiple scattering of the detected particles in the gas cell exit foil may be significant. Using the methods in Ref. 9, we found these effects not to contribute a significant error in this experiment.

\section{Differential Cross Sections}

The laboratory cross sections $\sigma_{\mathrm{o}}$ were computed from the formula

$\sigma_{\mathrm{o}}\left(\theta_{\mathrm{o}}\right)=\frac{Y \sin \theta_{0}}{\mathrm{n} \mathrm{NG}}$,

where $Y$ is the number (yield) of scattered particles (corrected for background and dead time), $\theta_{0}$ is the laboratory scattering angle, $\boldsymbol{n}$ is the number of beam particles, $\mathbf{N}$ is the number of target particles per unit volume, and $\mathbf{G}$ is the gas-target geometry factor. ${ }^{16}$ For our symmetric geometry, the yield is the average of the yield of the left and right detectors. Cross sections are not quoted for $\theta_{\mathrm{c} . \mathrm{m} .}=25^{\circ}$ or $155^{\circ}\left(\theta_{\mathrm{o}}=12.5^{\circ}\right)$ because the detector collimator assemblies intercepted some of the beam leaving the gas target.

The relative errors in the cross-section data arise mainly from (1) reading the capacitance manometer pressure gauge, (2) counting statistics, (3) the method of background subtraction, (4) random pressure and temperature fluctuations in the target, (5) beam-current integration, and (6) beam-position instability and/or detector-position uncertainty. We estimate that the total error caused by items (1), (3), (4), (5), and (6) is $1.0 \%$, based on previous LASL experiments with similar targets and on the geometry of the supercube scattering chamber. We expected the total relative error to equal the statistical error plus $1.0 \%$, but it became apparent, even with a small statistical error, that an unknown systematic error was dominating the relative error. A careful study of this systematic effect resulted in the assignment of a relative error of $\pm 2.0 \%$ for triton detection and $\pm 2.5 \%$ for alpha detection.

The scale errors for the cross section may be traced to (1) calibration of the pressure gauge, (2) calibration of the current integrator, (3) purity of the target gas, and (4) geometry factor $G$. The error caused by calibration of the pressure gauge is $1.0 \%$, whereas that caused by calibration of the current integrator is of the order $0.2 \% .^{17}$ The slits used in the experiments were measured with a Lietz split-image optical comparator: from these measurements, we can estimate the $G$ factor to $\pm 0.2 \%$ 
accuracy. The first-order correction to G (Ref. 16, Eq. $(5 c) .1)$ is $0.07 \%$, so deviations of $G$ from $G_{0 o}$ are of no consequence. The overall scale error we assign to our data is, therefore, $1.1 \%$.

At higher energies, the sharpness of the forward-and backward-angle minima and the steep slopes in the angular distributions suggest a possible need for multiplescattering corrections. ${ }^{9.18}$ We estimated these corrections and found them to be small.

For both analyzing power and cross section, the $\pm 0.02^{\circ}$ (lab angle) uncertainty in the detector position possibly could contribute to the relative error in regions where the angular distribution has a steep slope. Calculations with the present data showed this effect to be negligible.

\section{V. DATA ANALYSIS}

Table I summarizes the energies and the number of data points at each energy and provides information on ${ }^{7} \mathrm{Li}$ energy levels for the reader's convenience. ${ }^{19}$ The items marked with an asterisk are previous data from LASL report LA $-6188^{\circ}$ and are repeated here for convenience. Appendix $\mathbf{A}$ is a complete numerical listing of the data. The superscripts " $t$ " and " $\alpha$ " on the lab angle indicate whether the triton or alpha particle was detected. The errors given for $A_{y}$ are relative errors; the relative errors for the differential cross sections are $\pm 2.0 \%$ for the triton-detected data and $\pm 2.5 \%$ for the alpha-detected data. In several cases where the triton and alpha data overlap, there is good agreement.

The data were taken in two groups. in the experiment measuring the data of group 2 (set 2 in Table I), the G-factor was not known precisely, so the absolute values of the cross sections were normalized to the accurate data of LASL report LA $6188^{5}$ by comparison of several overlapping points at 8,9 , and $10 \mathrm{MeV}$. The data of group 1 (set 1 in Table I) were absolute measurements. Twelve-MeV data were also measured previously, as reported in LASL report LA-6188. ${ }^{5}$ Comparison with this more accurate previous data $( \pm 0.4 \%$ scale error) provided a verification of our present absoiste errors. For our alpha-detected data we agreed to $1.3 \%$, and for the triton-detected data we agreed to $0.2 \%$. This good agreement reassured us that our gas purity, current integration, and other absolute scale factors were well understood. The experimental procedure for the LASL report LA-6188 cross-section data ${ }^{5}$ has never been published and is given in Appendix B to support our present results.
TABLE I

\section{DATA SUMMARY AND ENERGY LEVEL INFORMATION ${ }^{\mathrm{a}}$}

\begin{tabular}{|c|c|c|c|}
\hline $\begin{array}{l}\text { Lab } \\
\text { Triton } \\
\text { Energy } \\
(\mathrm{MeV})\end{array}$ & $\begin{array}{c}\text { Number of } \\
\sigma(\theta) \text { Data } \\
\text { or }\left[J^{n}, T\right]\end{array}$ & $\begin{array}{c}\text { Number of } \\
A_{y} \text { Data } \\
\text { or [width } \\
\text { (keV)] }\end{array}$ & $\begin{array}{c}\text { Data } \\
\text { Set } \\
\end{array}$ \\
\hline 3.793 & {$\left[7 / 2^{-}, 1 / 2\right]$} & [93] & --- \\
\hline 6.000 & 11 & 14 & 2 \\
\hline 7.000 & 20 & 26 & 2 \\
\hline 7.387 & {$\left[5 / 2^{-}, 1 / 2\right]$} & {$[875]$} & -- \\
\hline 8.000 & 25 & 25 & 2 \\
\hline 8.388 & ${ }^{6} \mathrm{Li}+\mathrm{n}$ threshold & -.- & -- \\
\hline 8.748 & {$\left[5 / 2^{-}, 1 / 2\right]$} & [90] & $\ldots$ \\
\hline 8.788 & $17^{*}$ & $29^{*}$ & -- \\
\hline 9.000 & 29 & 28 & 2 \\
\hline 10.000 & 27 & 27 & 2 \\
\hline 10.815 & 26 & $38^{*}$ & I \\
\hline 11.000 & 29 & 28 & 2 \\
\hline 12.000 & 30 & 30 & 1 \\
\hline 12.250 & 26 & $26^{*}$ & 1 \\
\hline 12.630 & {$\left[7 / 2^{-}, 1 / 2\right]$} & {$[400]$} & -- \\
\hline 12.626 & 30 & 30 & 1 \\
\hline 12.800 & 31 & 31 & 2 \\
\hline 12.945 & {$\left[3 / 2^{-}, 1 / 2\right]$} & {$[1200]$} & -.. \\
\hline 13.000 & 30 & 30 & 1 \\
\hline 13.270 & 30 & 30 & 2 \\
\hline 13.548 & 30 & 30 & 2 \\
\hline 13.748 & 31 & 31 & 2 \\
\hline 14.000 & 31 & 31 & 1 \\
\hline 15.000 & 31 & 32 & 1 \\
\hline 15.383 & {$\left[3 / 2^{-}, 3 / 2\right]$} & {$[260]$} & $\cdots$ \\
\hline 16.000 & 31 & 32 & 1 \\
\hline 17.000 & 30 & 31 & 1 \\
\hline
\end{tabular}

'Asterisks indicate previous data from Ref. $\$$. 
Out of 1065 data points measured, 46 were discarded for the following reasons: equipment malfunction, 9 points; detector-assembly interception of the beam at low angles and low energies, 2 points; excessive change in detector efficiency, 29 ponts; and excessive beam polarization changes, 6 points. In addition, four analyzing power points and one cross-section point deviated anomolously from the smooth curve of nearby points (with $\chi^{2}>16$ ) and were discarded. The occasional gross changes in detector efficiency were not understood.

\section{v. DISCUSSION}

Figures 2-8 show the angular distributions of the differential cross sections and of the analyzing power $A_{y}$ at the various bombarding energies. They demonstrate remarkable changes in the shape of the analyzing powers as a function of energy. Of particular note is the $A_{y}=-1$ extremum $^{6}$ in the region of $10.185 \mathrm{MeV}$ at about $90^{\circ}$ c.m. We are analyzing the data with an energy-independent phase-shift code HALBNUL developed by F. D. Correll. This code derives from the Zürich code EINSNUL ${ }^{20}$ and uses the minimization program MINUIT. ${ }^{21}$ The dotted lines in Figs. 2-8, which have converged in most cases with a reasonable $\chi^{2}$ per degree of freedom, are the preliminary results of the analysis. Our data at $17.000 \mathrm{MeV}$ have been compared ${ }^{22}$ with the predictions of an RGM calculation ${ }^{2}$ with reasonable agreement.

\section{ACKNOWLEDGEMENTS}

This project has benefited from the assistance of many people, in particular Dave M. Stupin, Richard F. Haglund, Jr., Louis Morrison, Rudy Martinez, and the operating staff of the Van de Graaff accelerators. We are also grateful to R. V. Poore, P. A. Schmelzbach, B. D. Anderson, and P. A. Lovoi. 

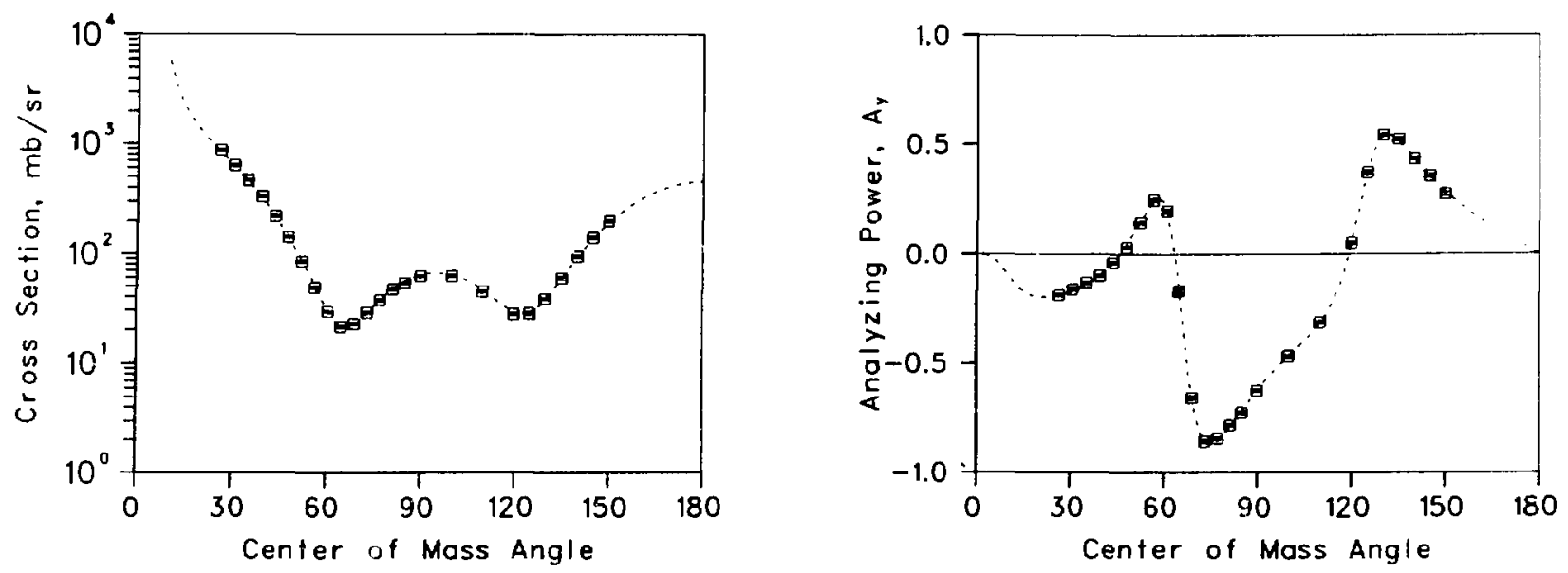

(c)
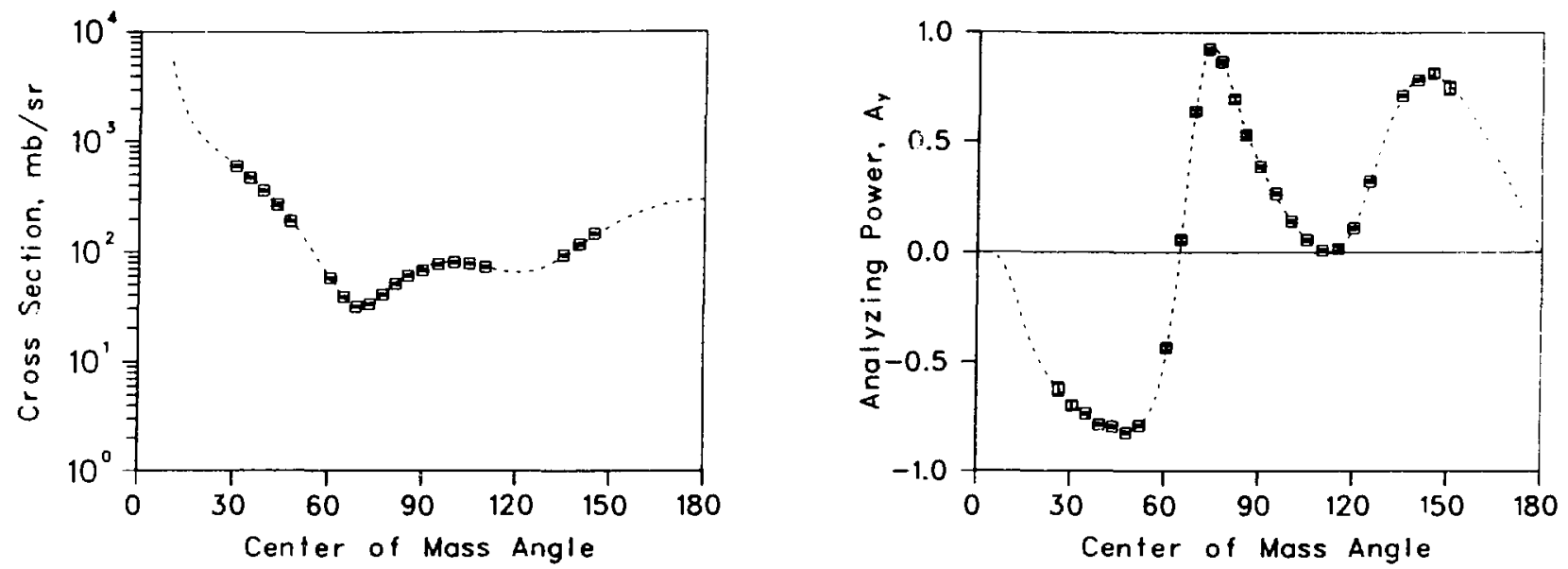

(b)
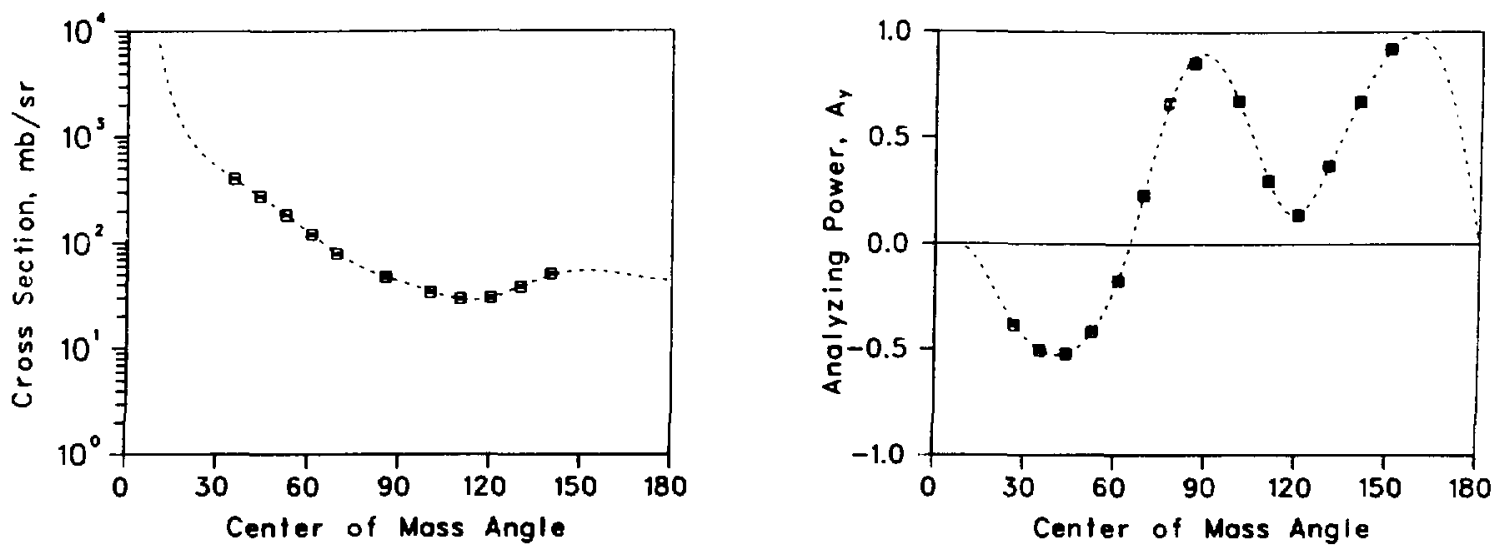

(a)

Fig. 2.

${ }^{4} \mathrm{He}(\mathrm{t}, \mathrm{t})^{\mathrm{H}} \mathrm{He}$ cross sections and analyzing powers at (a) 6.000 , (b) 7.000 , and (c) $8.000 \mathrm{MeV}$. The angles are in degrees, and the curves are fits by an energy-independent phuse-shif analysis. 

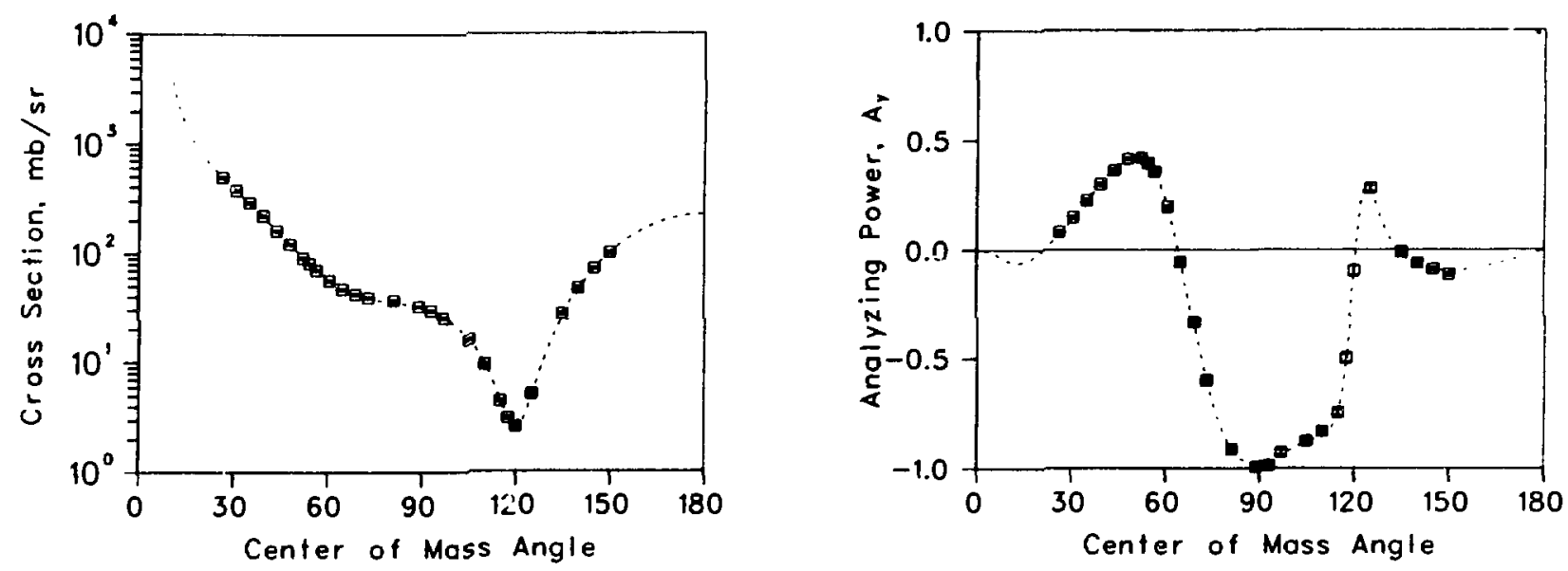

(c)

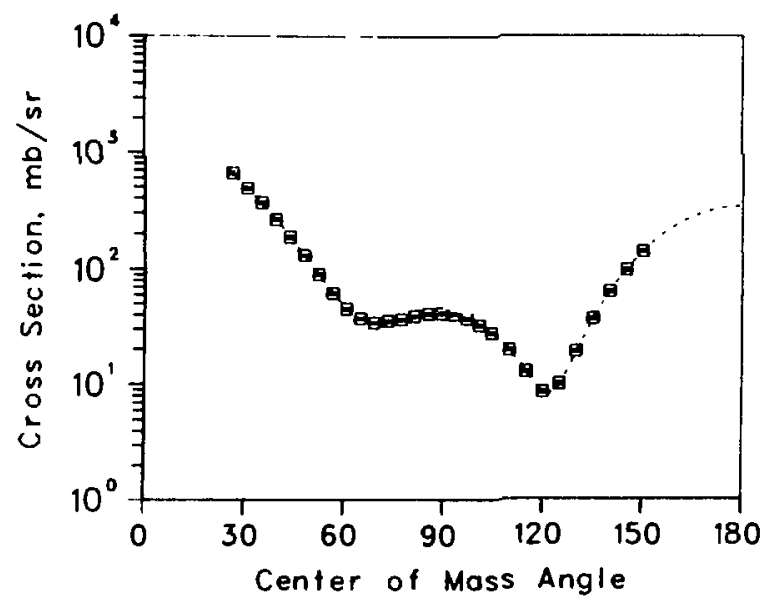

(b)
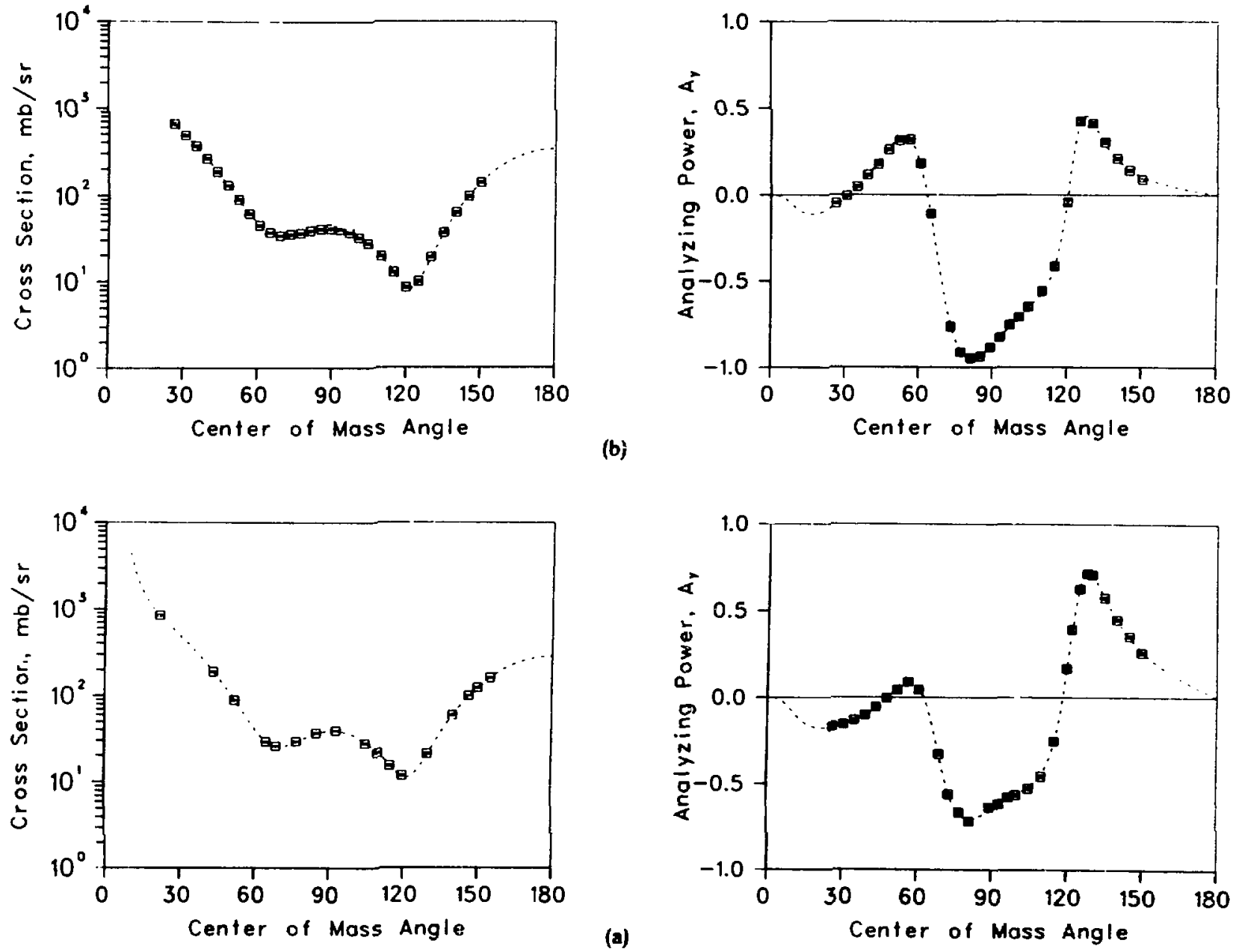

Fis. 3 .

${ }^{4} \mathrm{He}(\mathrm{t}, \mathrm{t})^{4} \mathrm{He}$ cross sections and analyzing powers at (a) 8.788, (b) 9.000, and (c) $10.000 \mathrm{MeV}$. The angles are in degrees, and the curves are fits by an energy-independent phase-shit analysis. 

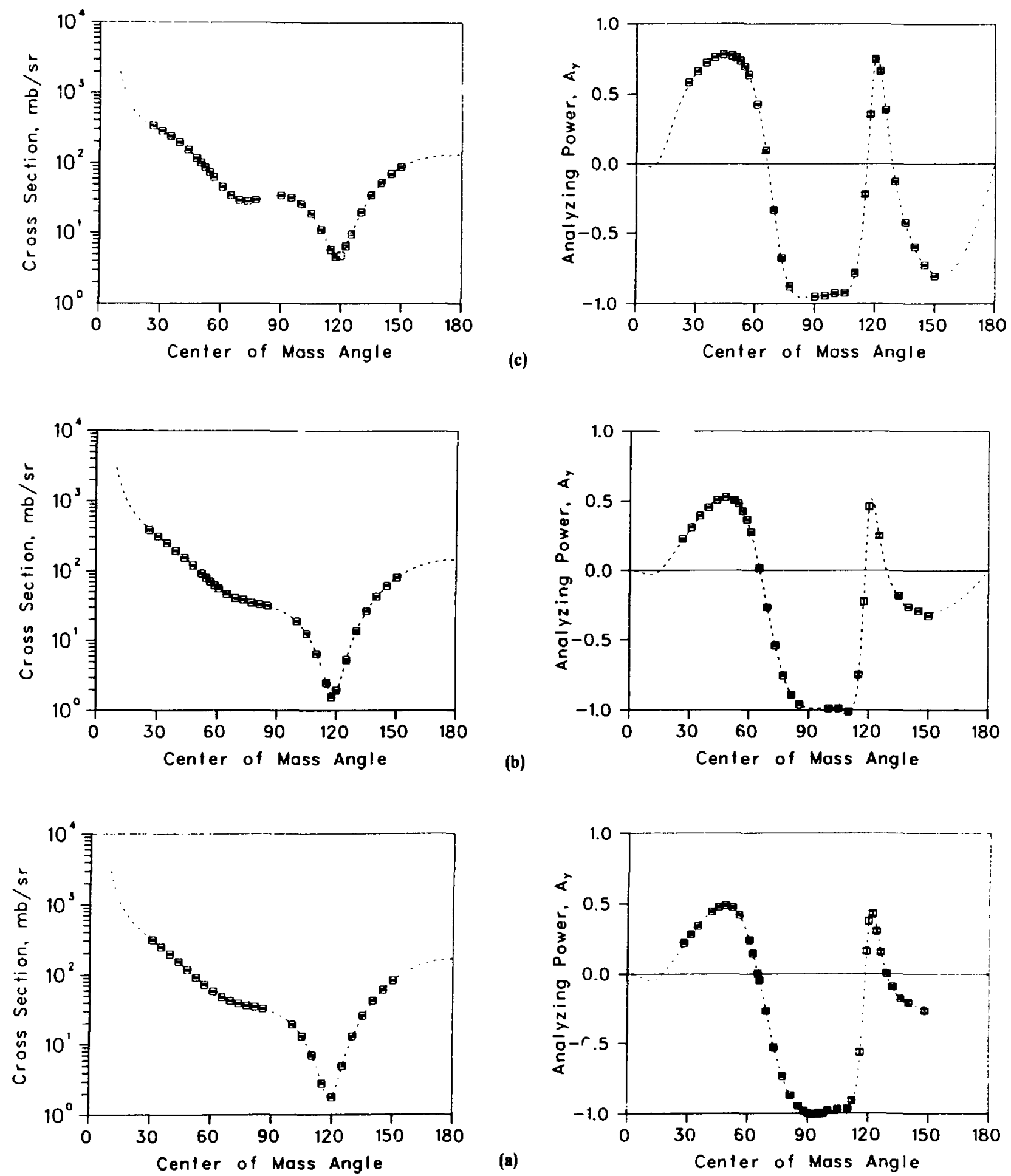

Fig. 4.

${ }^{4} \mathrm{He}(\mathrm{t}, \mathrm{t})^{4} \mathrm{He}$ cross sections and analyzing powers at (a) 10.815 , (b) 11.000 , and (c) $12.000 \mathrm{M}=\mathrm{V}$. The angles are in degrees, and the curves are fits by an energy-independent phase-shif analysis. 

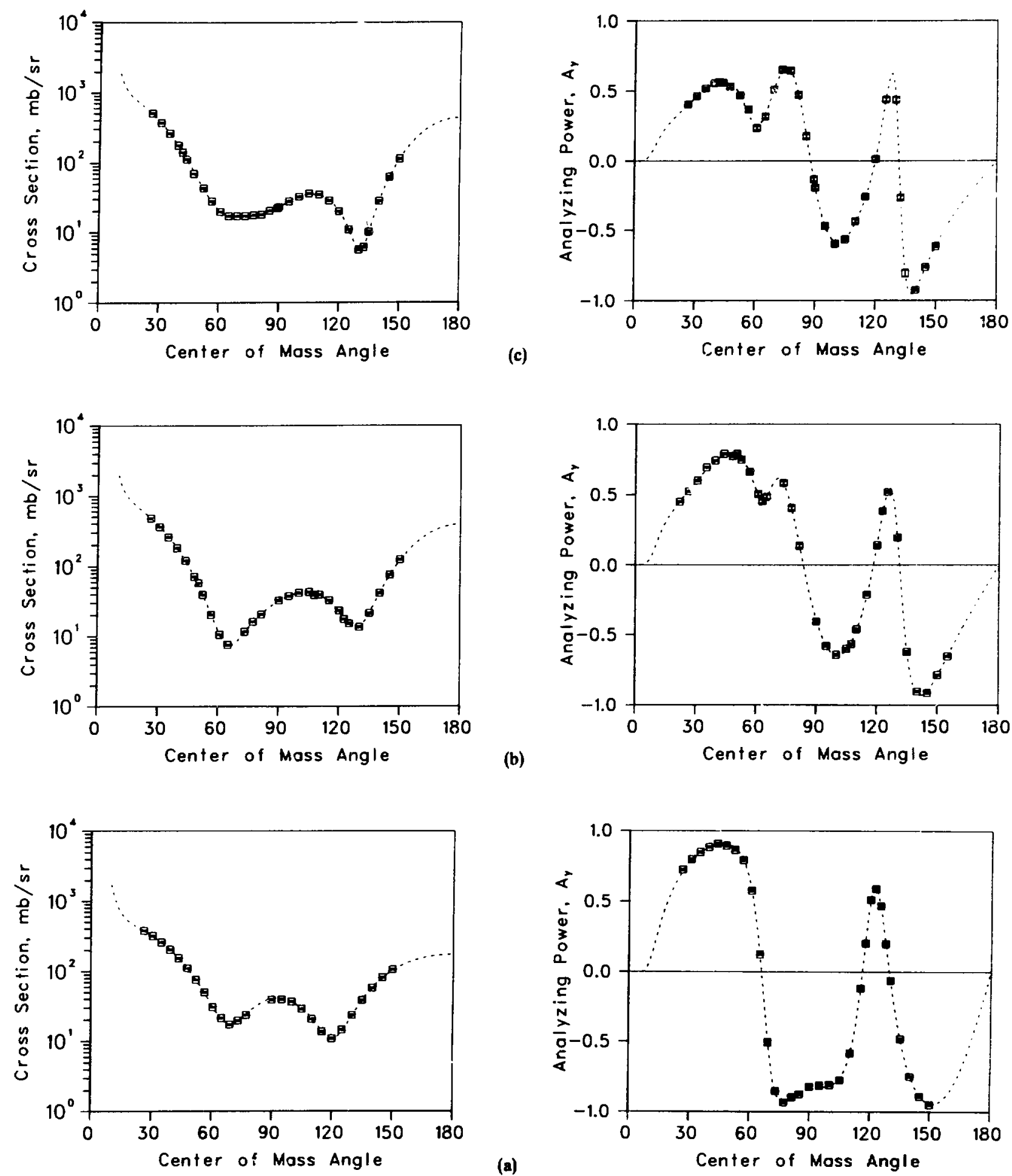

Fig. 5.

${ }^{4} \mathrm{He}(\mathrm{t}, \mathrm{t})^{4} \mathrm{He}$ cross sections and analyzing powers at (a) 12.250 , (b) 12.626 , and (c) $12.800 \mathrm{MeV}$. The angles are in degrees, and the curves are fits by an energy-independent phase-shift analysis. 

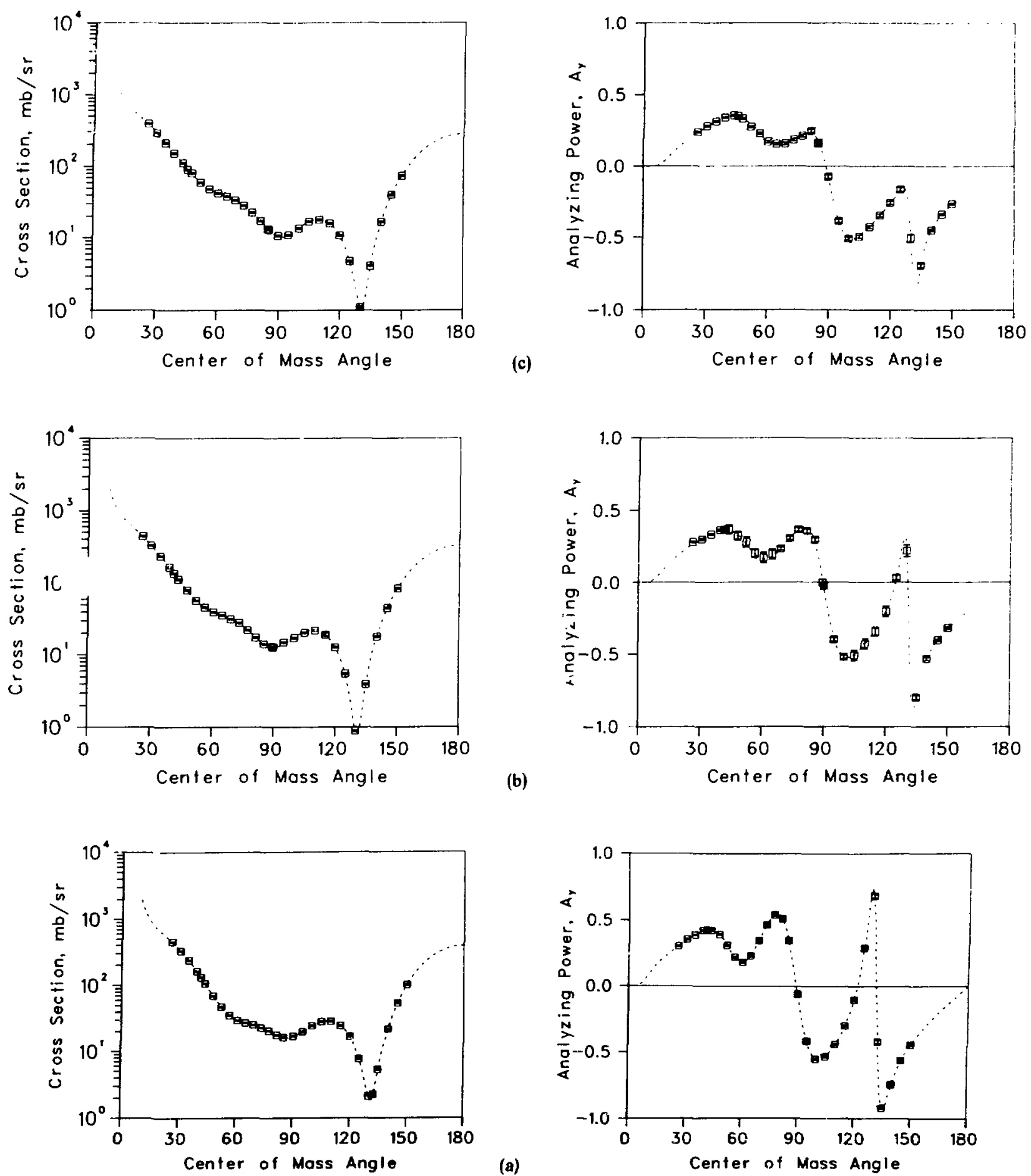

Fig. 6.

${ }^{4} \mathrm{He}(t, t)^{4} \mathrm{He}$ cross sections and analyzing powers at (a) 13.000 , (b) 13.270 , and (c) $13.548 \mathrm{MeV}$. The agles are in degrees, and the curves are fits by an energy-independent phase-shift analysis. 

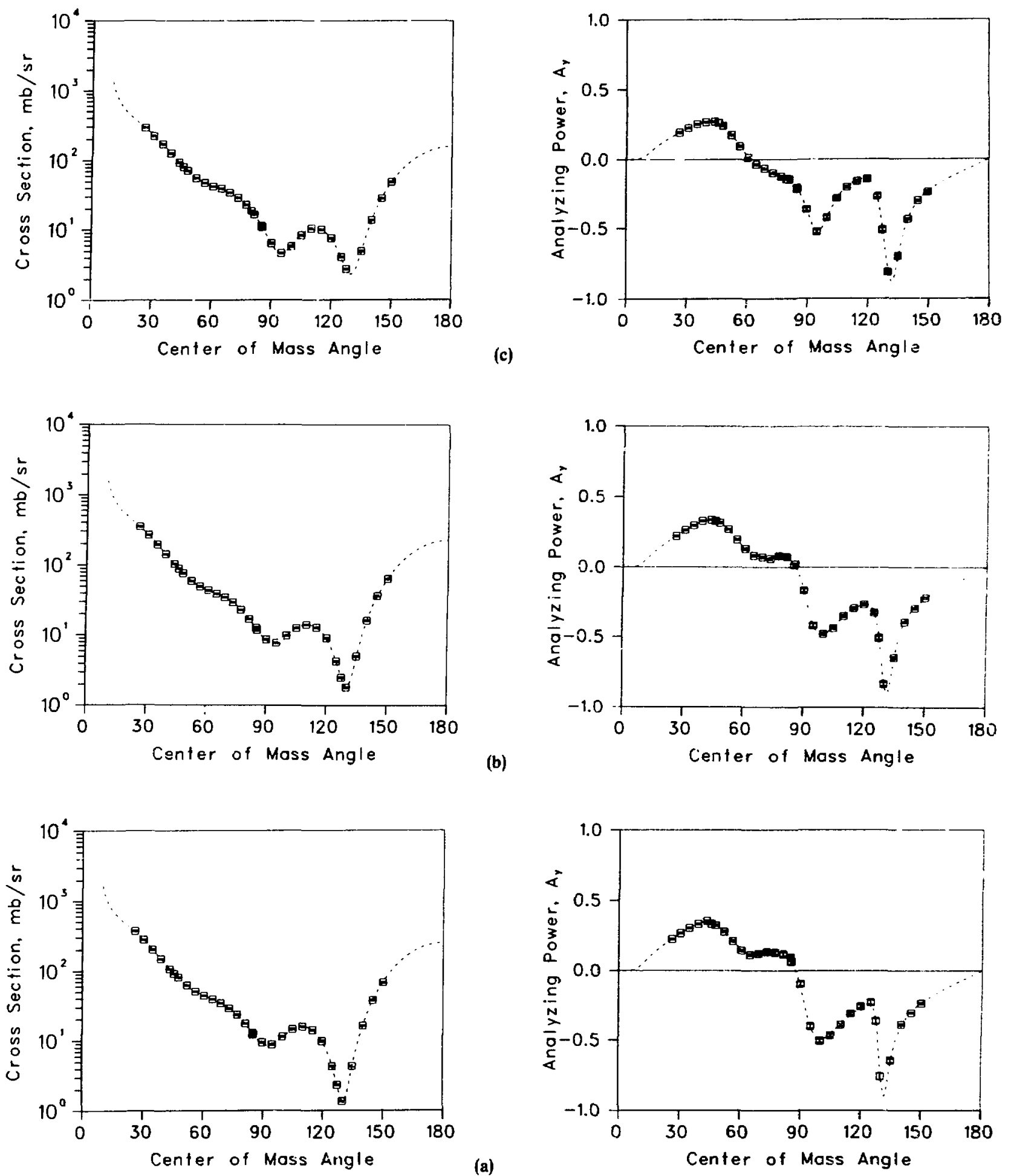

(a)

(b)

(c)

Fig. 7.

${ }^{4} \mathrm{He}(\mathrm{t}, \mathrm{t})^{4} \mathrm{~Hz}$ cross sections and analyzing powers at (a) 13.748 , (b) 14.000 , and (c) $15.000 \mathrm{MeV}$. The angles are in degrees, and the curves are fits by an energy-independent phase-shift analysis. 

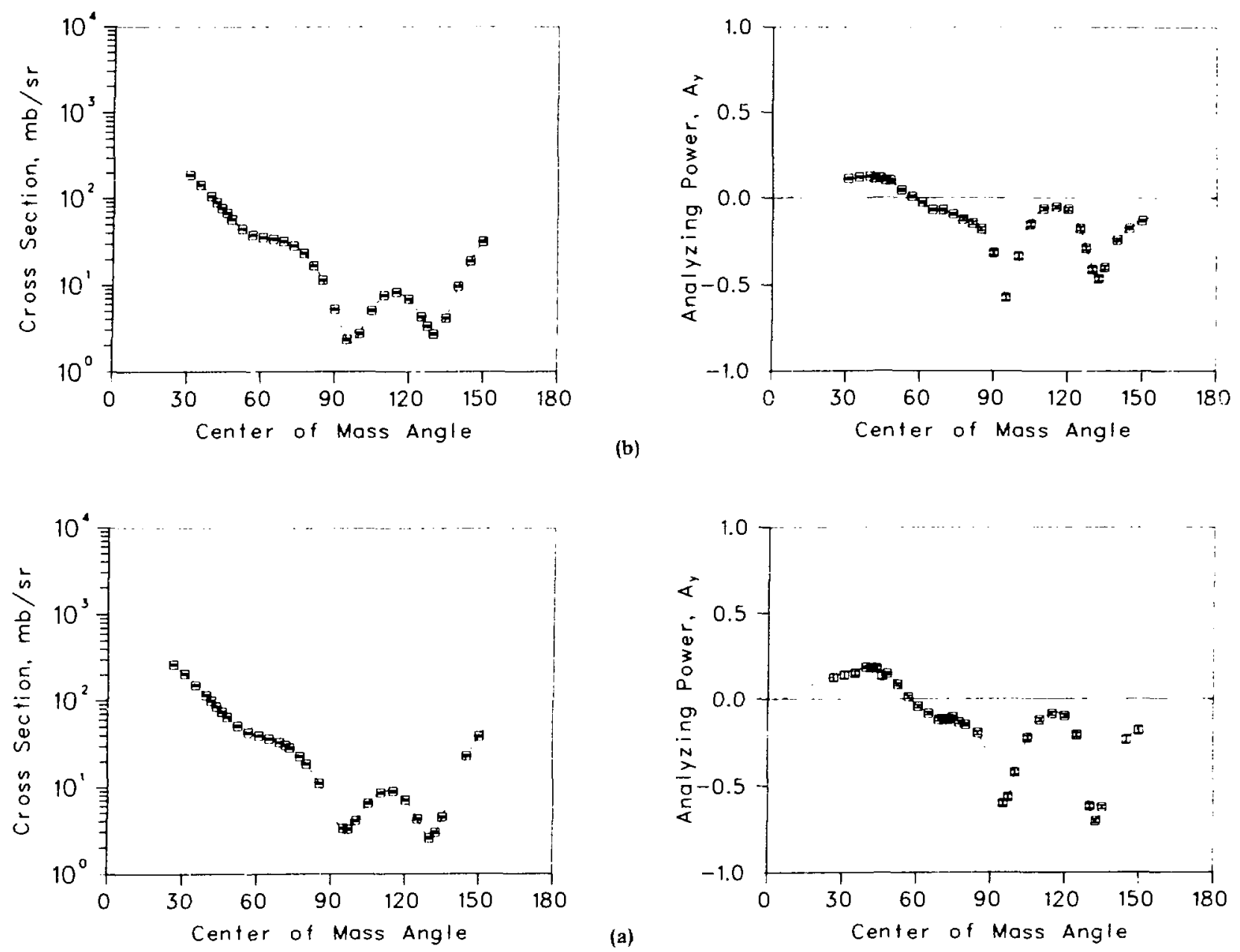

(b)

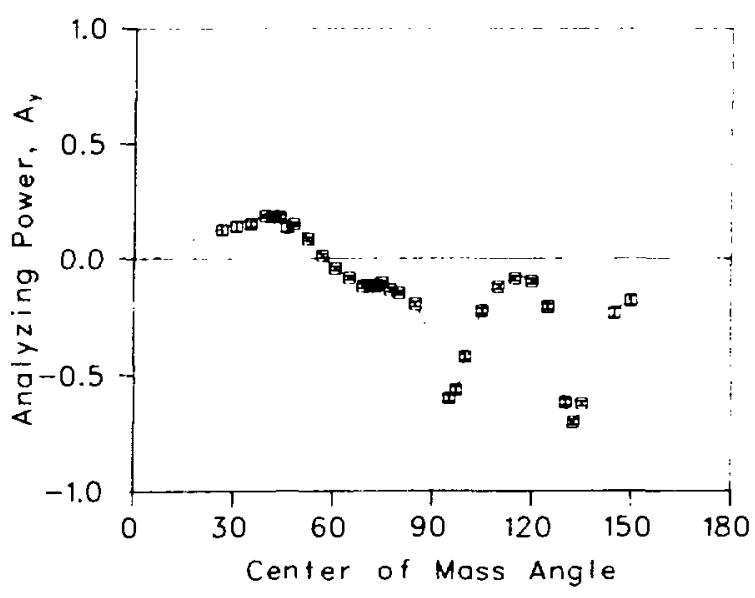

Fig. 8.

${ }^{4} \mathrm{He}(\mathrm{t}, \mathrm{t})^{4} \mathrm{He}$ cross sections and analyzing powers at (a) 16.000 and (b) $17.000 \mathrm{MeV}$. The angles are in degrees, and the curves are fits by an energy-independent phase-sinift analysis. 


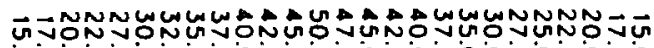
U.t.

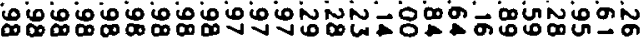

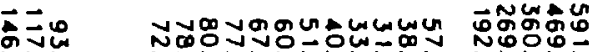

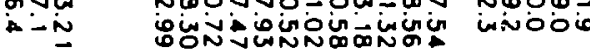

0000000000000000000000000000 No ju

00000000000000000000000000 แัง

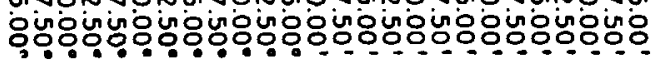

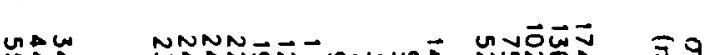

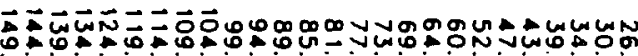

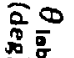
照票

$\frac{\bar{n}}{\frac{\pi}{2}} \frac{\overline{1}}{\frac{1}{0}}$

$\frac{1}{3}$

䓎

吕吕

"1

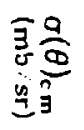

2

?

家

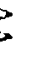

需要

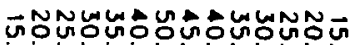

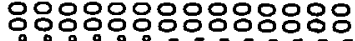

高市

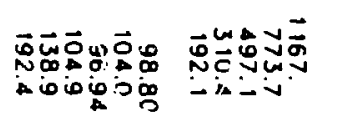

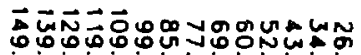
:

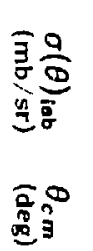

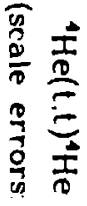

吕只

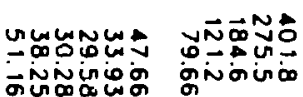

率高

00000000000óón

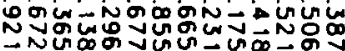

00000000000000

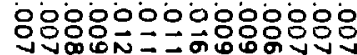

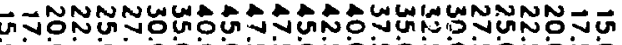
هั

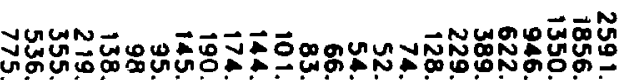

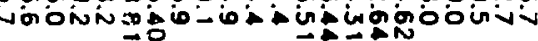

ZิF

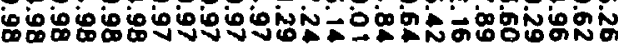

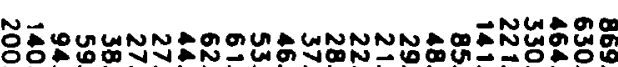

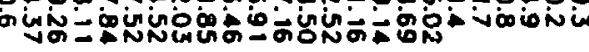

- o00000óóóóóóboopodódón

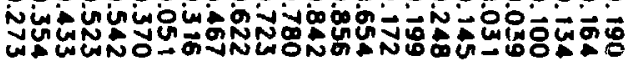

" 9 :8 $\geqslant \frac{2}{3}$

"
产

11 象 8 足交

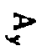
" 


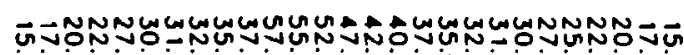

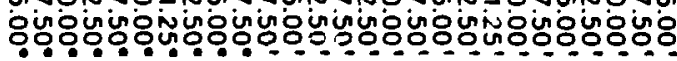
WNN

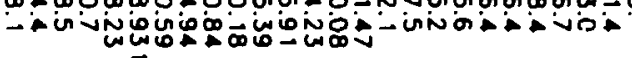

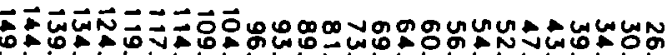
\$ow

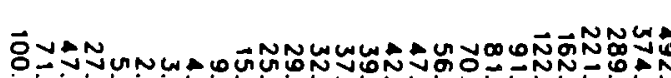

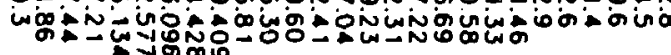

óóóoóóóóóóódóóó0000000000

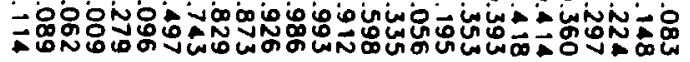

章要 青衣

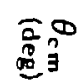

当응 is

(1)

$+$

000000000000000000000000000

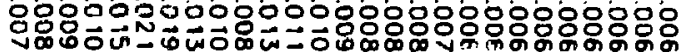

$\stackrel{5}{2}$

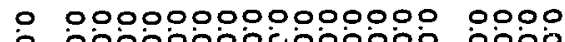

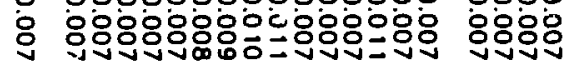

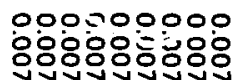

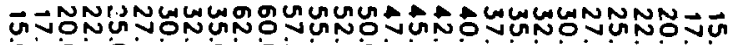

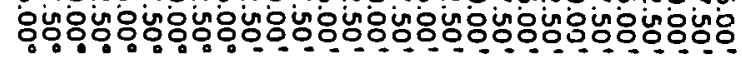

$\frac{3}{3} \frac{1}{2}$

$\frac{3}{3}$

$\frac{\bar{\sigma}}{\mathrm{D}}$

눙

$1 \overline{0}$

용요

$2 \frac{1}{2}$

" $\bar{a}$

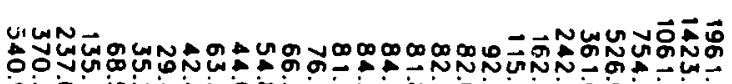

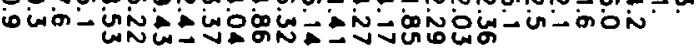

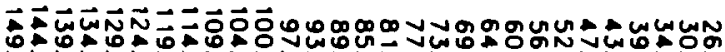

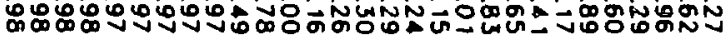

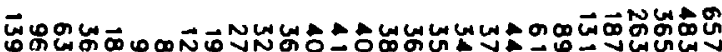

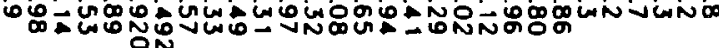

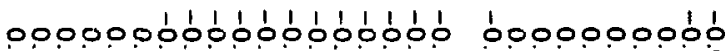

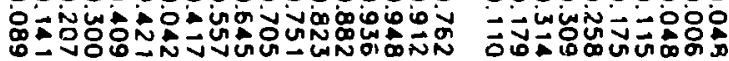

0000000000000000000000000000

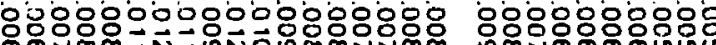
3 " $\overline{\bar{g}}$

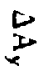




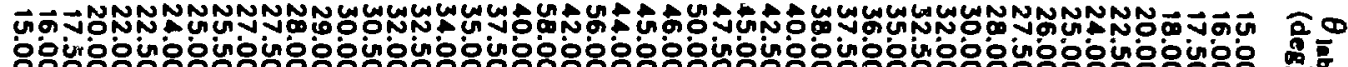

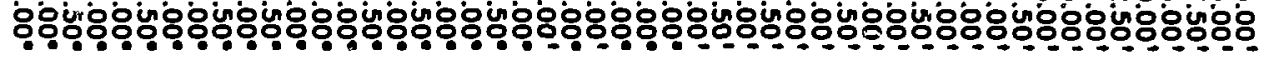

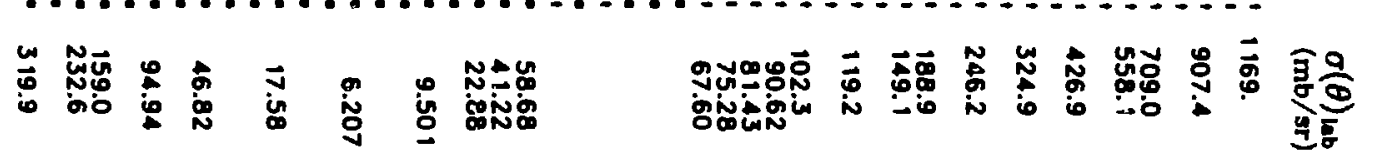

牙

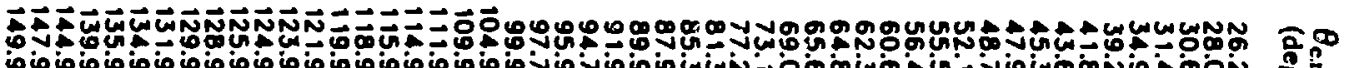
๑ø:

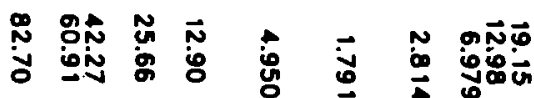

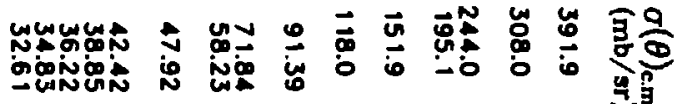

$\| \sigma$

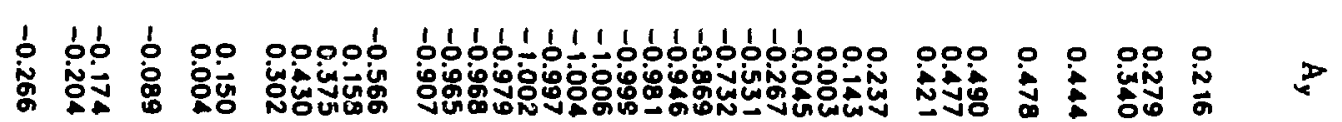

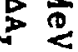

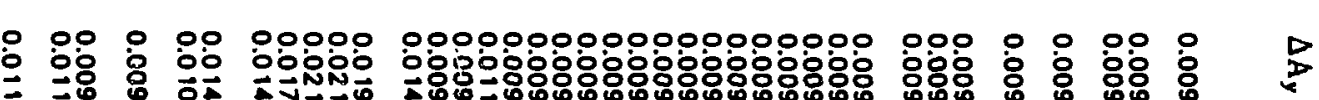

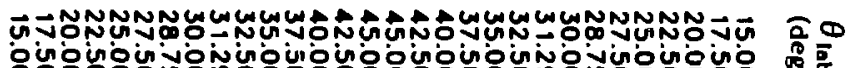

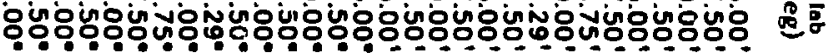

ผำ

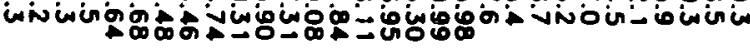

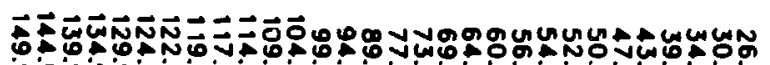

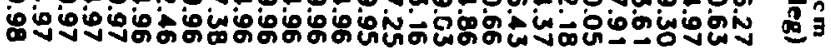

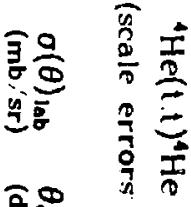

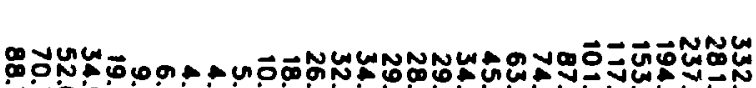

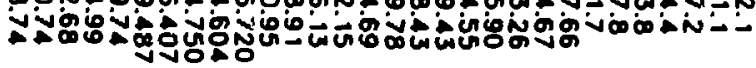

bóóóóo000óóóóblób000000000000

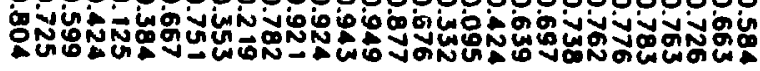

000000000000000000000000000000

ริำ

安 $" \overline{\frac{\sigma}{\sigma}}$

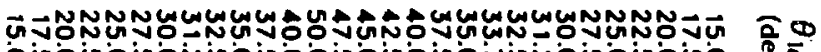

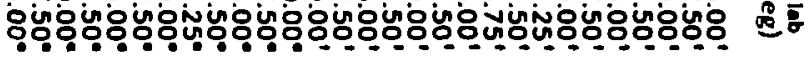

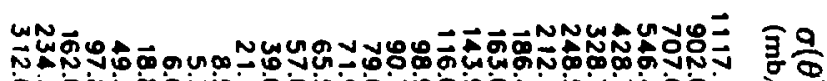

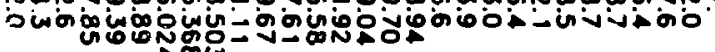

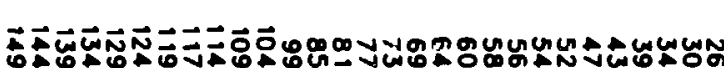

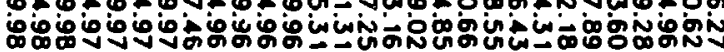

高

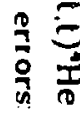
吕只

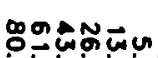
givîñ WO-

$"=$

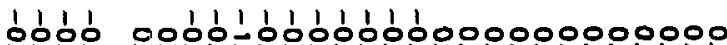

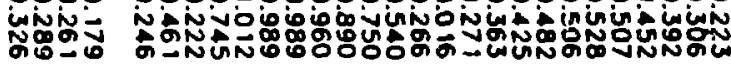
要金

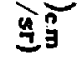
$3 \frac{2}{2}$

0000000000000000000000000000

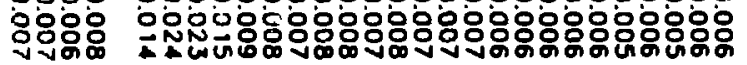


₹

j o000000000000000000000000000000

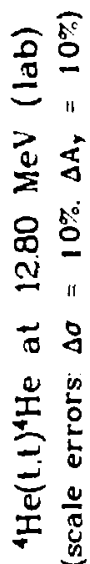

$\varangle$

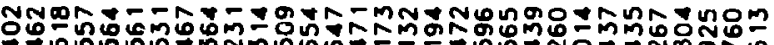
0000000000000000ipipipipo000ipipi

Еโ กั

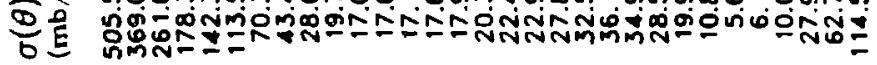

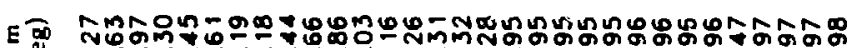

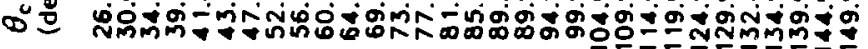

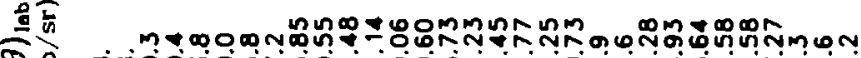

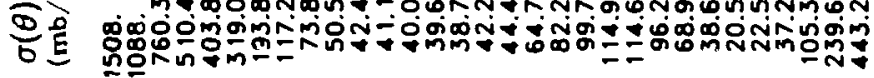

๔ o

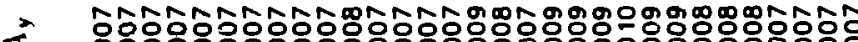

ব 00000000000000000000000000000000

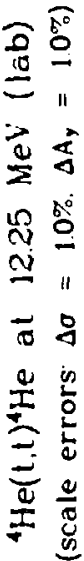

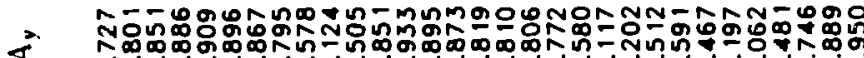

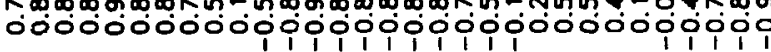

Eี

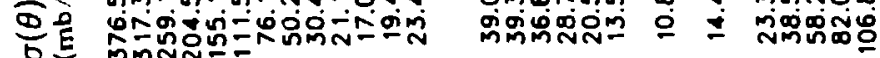

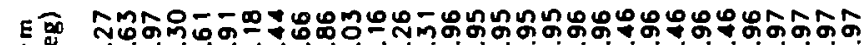

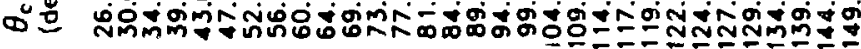

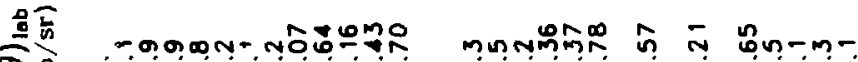

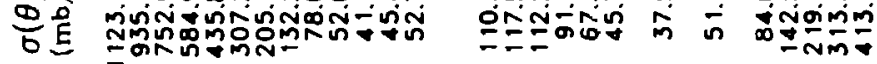

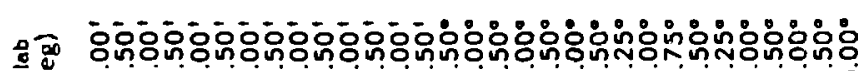
o:

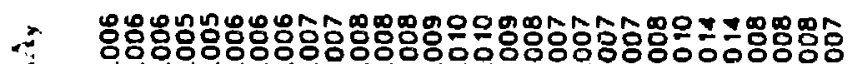

4 0000000000000000000000000000

음

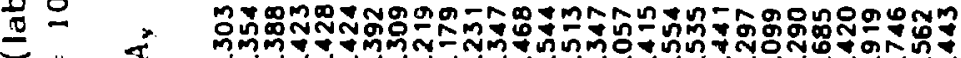

- o0000000000000ipipipoupipi

$\frac{2}{2}$

용 옹

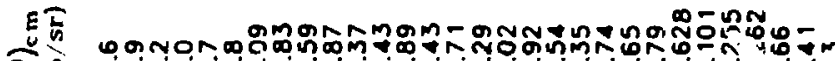

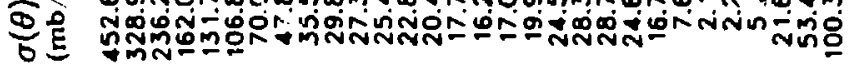

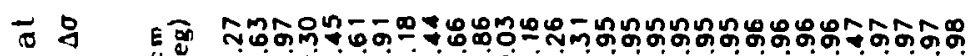

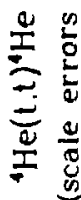

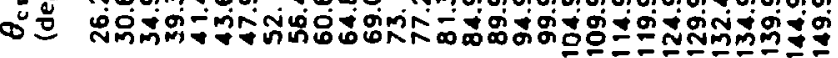

ำ

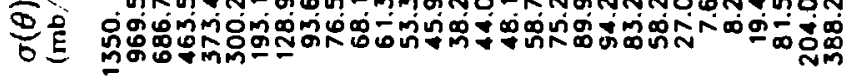

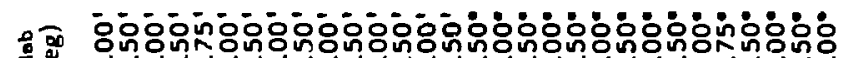

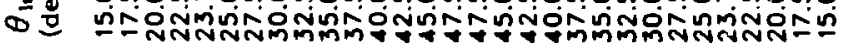

×

子

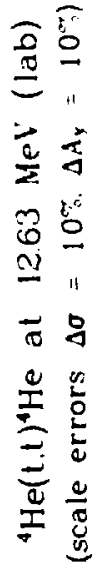

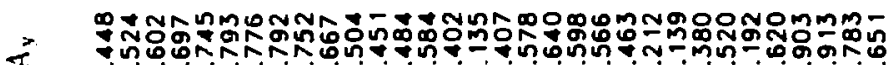
o000000000000000ipipipóo0ipipi

Ẽ

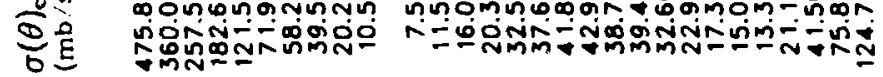

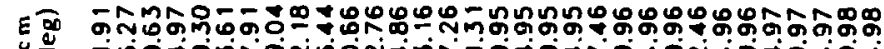

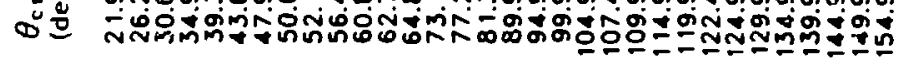

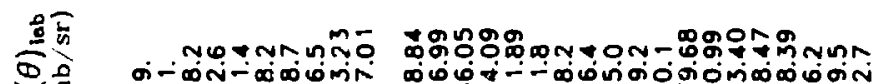

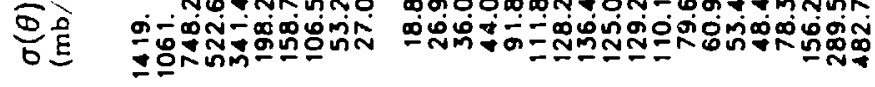

\&

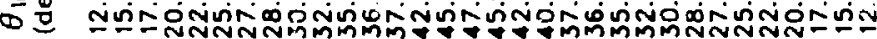




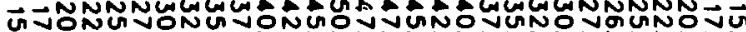

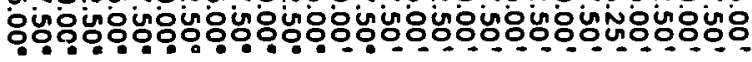

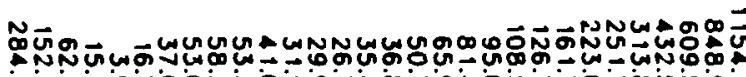

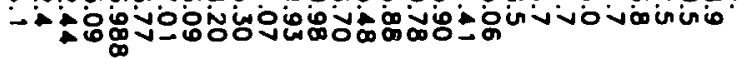

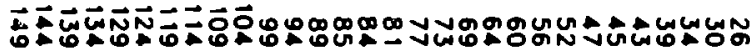

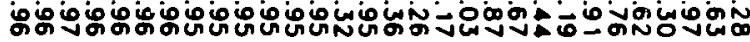

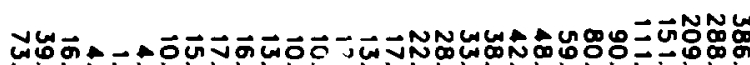

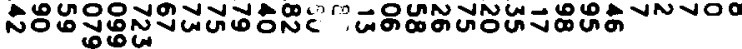

óóóóbóólódólo0000000000000000

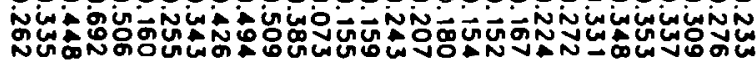

000000000000000000000000000000

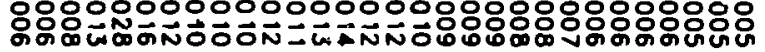

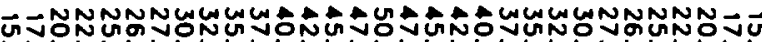

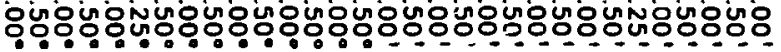

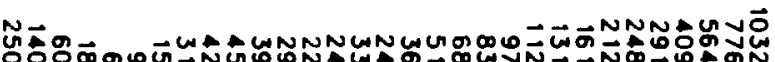

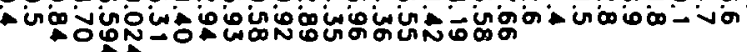

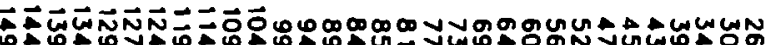

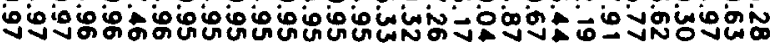

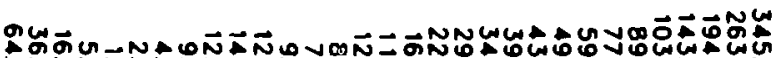

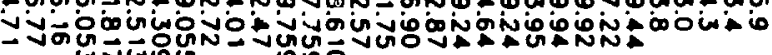

b́óblódólólóló00000000000000000 Nivis

0000000000000000000000000000000

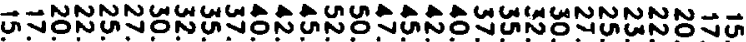

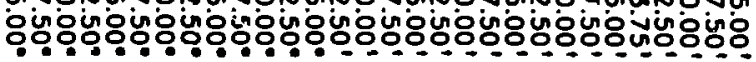

高客

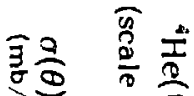

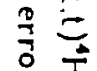

बक के

吕

$" \bar{\omega}$

章星 $\overline{0}$

$2 \frac{1}{2}$

$+11$

$\overline{\overline{0}} \overline{\frac{\overline{2}}{5}}$

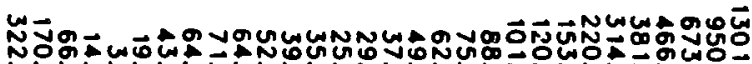

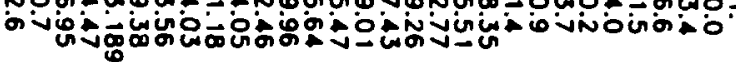

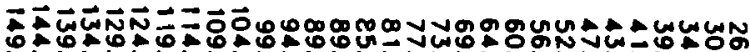

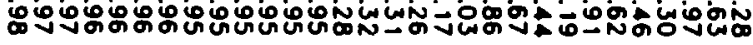

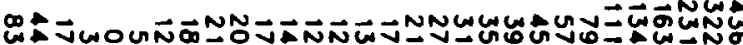

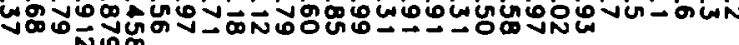

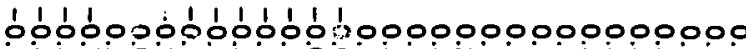
$3 \frac{3}{2}$

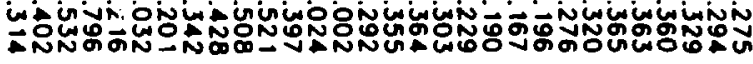

000000000000000000000000000000

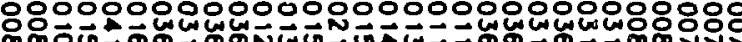

2

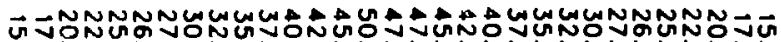

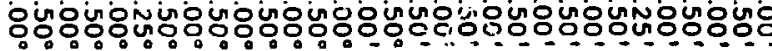

高要

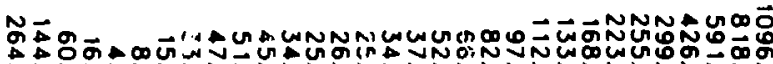

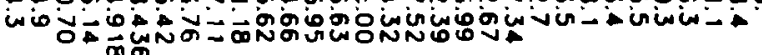

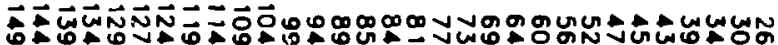

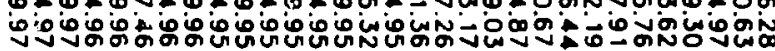

鱼 $\stackrel{2}{\frac{2}{2}}$

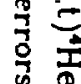
$\widehat{a} \infty$ 吕总

$\|$

ONN

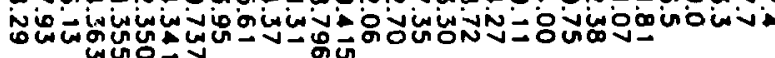

ĺóbólóbólóbóób000000000000000000

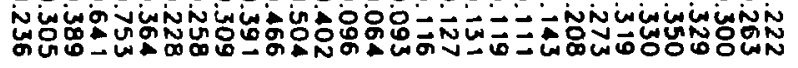

0000000000000000000000000000000

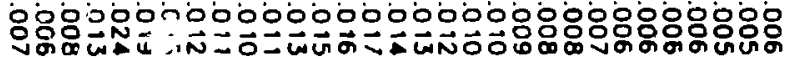




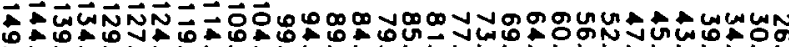

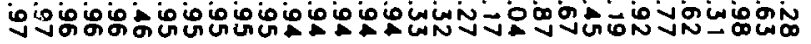

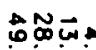

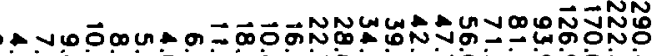

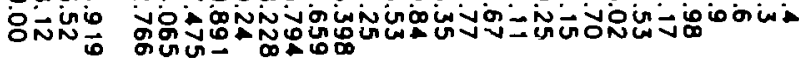

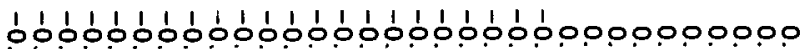

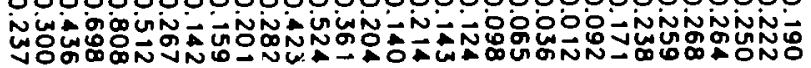

00000000000000000000000000000000

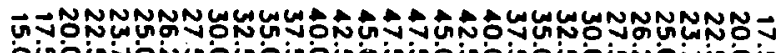
\%ัด

กิกับิ

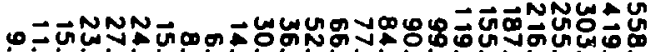

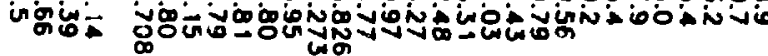

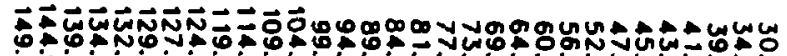

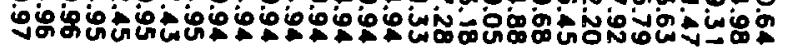

W0

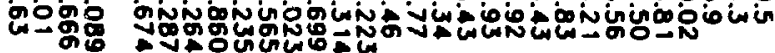

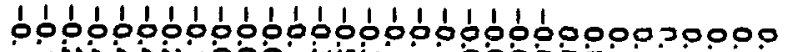

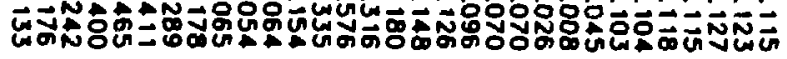

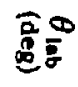

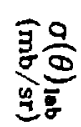

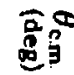

䨔高
कृ

$\frac{\mathrm{m}}{\mathrm{O}}$

究

吕哭

" $\rightarrow$

붕

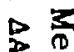

32

幽

0000000000000000000000000000000 ดัง

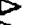

๑ง

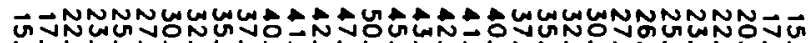
ठำง

竞宗

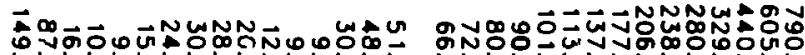

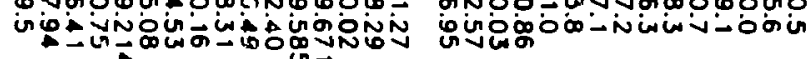

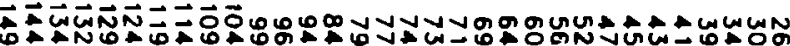

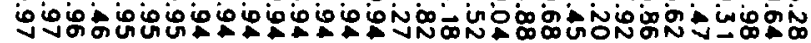

$\operatorname{win}_{\operatorname{mon}}$

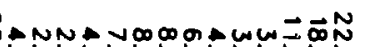

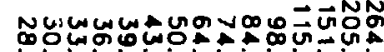

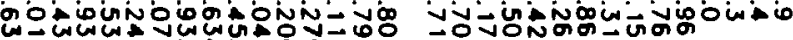

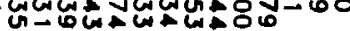

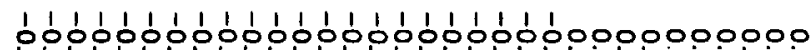

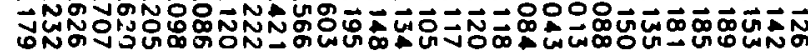

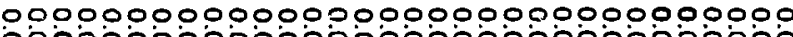

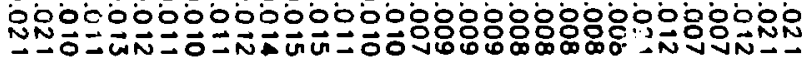




\section{APPENDIX B}

\section{EXPERIMENTAL PROCEDURE FOR ' $\mathrm{He}(\mathrm{t}, \mathrm{t})^{4} \mathrm{He}$ CROSS-SECTION DATA GIVEN IN LASL REPORT LA-6188}

\section{INTRODUCTION}

The accurate cross-section data published in LASL report LA-6188 ${ }^{3}$ provide the normalization for much of the differential cross-section dz:a of this report (see Sec. IV of the main text). The experimental procedure for LASL report LA-6188 cross-section data ${ }^{3}$ has never been published and is given below to support our present results.

\section{EXPERIMENTAL EQUIPMENT}

A triton beam from the LASL tandem Van de Graaff accelerator entered a $76.2-\mathrm{cm}$ scattering chamber ( $30 \mathrm{ir}$. ORTEC chamber) and passed through a ${ }^{4} \mathrm{He}$ gas target with thin 2.3- $\mu \mathrm{m}$ Havar foil windows. The experimental apparatus is described in detail by Jarmie et al. ${ }^{17}$ Scattered particles were detected by a single E- $\triangle \mathbf{E}$ detector arrangement using solid-state detectors $44-\mu \mathrm{m}$ thick (area $100 \mathrm{~mm}^{2}$ ) and $695-\mu \mathrm{m}$ thick (area $150 \mathrm{~mm}^{2}$ ). Beam currents incident on the target ranged between 10 and $600 \mathrm{nA}$ at a level adjusted to keep the counting rate safe. Amplified pulses from both detectors, gated by the $E-\triangle E$ counter, were digitized and sent to an on-line computer for mass analysis and storage.

Purity of the spectroscopic grade " $\mathrm{He}$ gas was determined by measuring the yield of the contaminant peaks in the triton spectra at a standard lab angle and standard incident triton energy ( $42.5^{\circ}$ and $9.844 \mathrm{MeV}$ ). These measurements were made at regular intervals during the course of the experiment so that the purity could be determined by interpolation for any time during the experiment. Cross sections for the contaminants were measured directly at the standard lab angle and energy in the scattering chamber with a known quantity of the contaminant gas in the gas target. Typical ${ }^{4} \mathrm{He}$ purity was $0.997 \pm 0.002$; carbon, oxygen, and hydrogen were the major contaminants. Gas in the target was changed approximately once a day. The pressure and temperature in the gas target were typically 160 torr and $25^{\circ} \mathrm{C}$. The pressure was measured with an accuracy of \pm 0.2 torr with a diaphragm capacitance-bridge transducer; the temperature was measured to $\pm 0.2^{\circ}$ with a Chromel-Alumel thermocouple. The geometry factor $(G)$ of $1.2 \times 10^{-5} \mathrm{~cm} \cdot \mathrm{sr}$ was determined by a ouble slit system of precision-machined nickel slits as described in Ref. 17.

\section{EXPERIMENTAL PROCEDURE}

To obtain a complete spectrum in the center of mass system, two methods were used to measure the cross sectic $n$. In the first method, the recoil tritons and alpha particles were detected at forward angles where the recoil energies were conveniently high. Triton (and alpha) spectra were measured in the manner described in Ref. 17 using the $E-\Delta E$ telescope. At angles greater than $\sim 15^{\circ}$, the energy of the recoil alphas was too low for these particles to pass through the $\triangle \mathbf{E}$ detector into the $E$ detector, and these events could not be mass-analyzed. The second method was used to measure the ${ }^{4} \mathrm{He}(\mathrm{t}, \alpha) \mathrm{T}$ cross section at angles greater than $\sim 15^{\circ}$ : the singles spectra from the $\Delta E$ detector alone were recorded simultaneously with $E-\triangle E$ coincidence events. When alpha peaks in the $\triangle E$ spectra were separate from the triton peaks and had low flat backgrounds, accurate cross sections could be extracted.

The accuracy of the single-counter technique was tested in the following manner. At angles where the kinetic energy of either the alphas or tritons was sufficient to obtain a mass-analyzed spectrum of the detected particle, the mass-identified spectrum was compared with the spectrum from the single detector. In these cases, the computed cross sections for the alphas or tritons from both spectra agreed to within statistical error.

Examples of spectra are shown in Figs. B-1-B-4. The logarithmic yield scale should be noted. In these spectra, the structure has been simplified for convenience in drafting the figures. The low background in the coincidence spectrum of Fig. B-1 is due to slit-edge scattering and contributed a subtraction to the main peak of from 0.5 to $1.0 \%$ for the triton spectra and the better alpha 


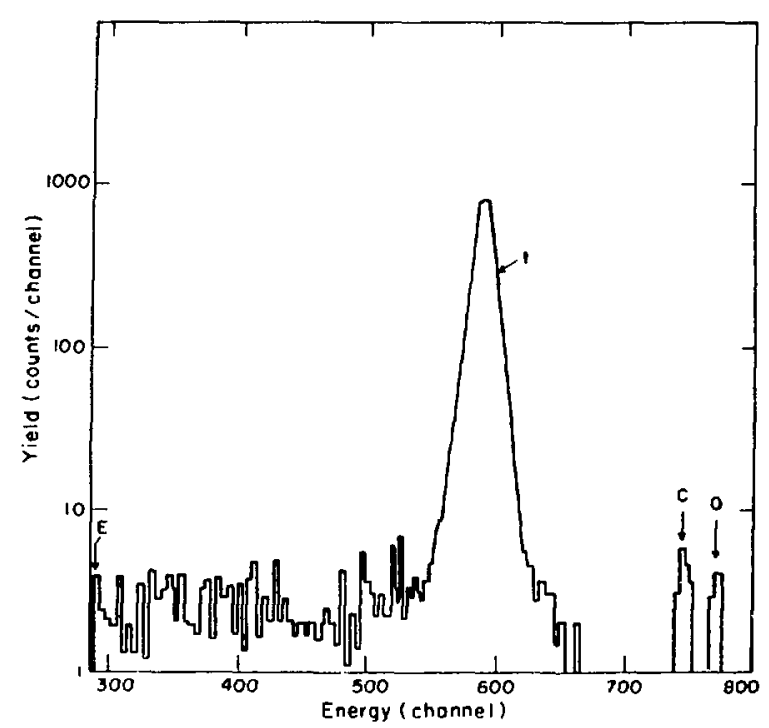

Fig. B-1

${ }^{4} \mathrm{He}(\mathrm{t}, \mathrm{t})^{\mathrm{H}} \mathrm{He}$ coincidence spectrum at $8.980 \mathrm{MeV}, 37.50^{\circ}$ (lab angle). The peak contains 58000 counts over a background of 500 counts. Further details are given in the text.

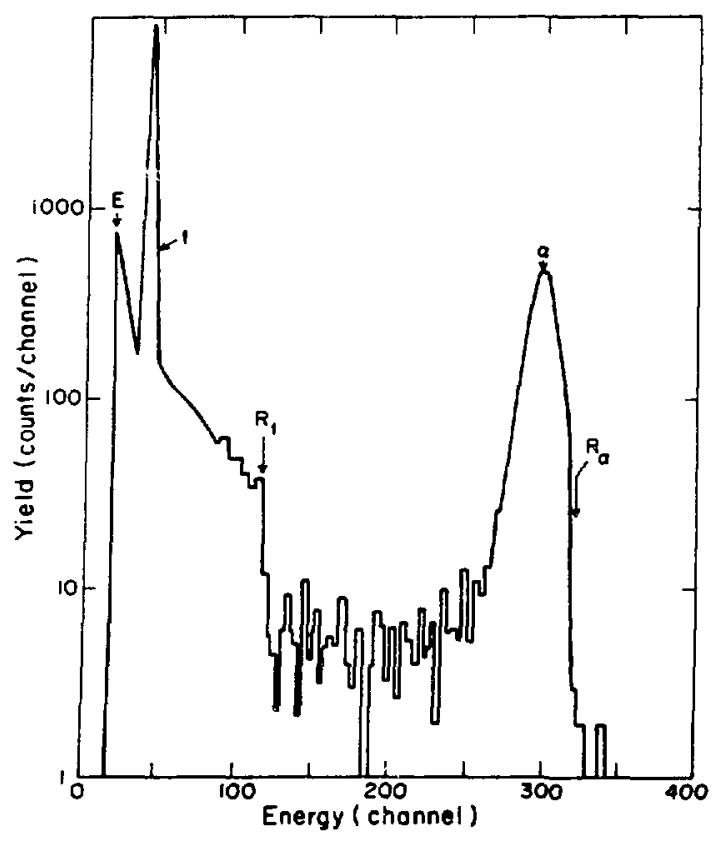

Fig. B-3

${ }^{+} \mathrm{He}(\mathrm{t}, \mathrm{a})$ ' $\mathrm{H}$ singles spectrum at $12.000 \mathrm{MeV}, 35^{\circ}$ (lab angle). The alpha peak contains 11000 counts over a background of 310 counts.

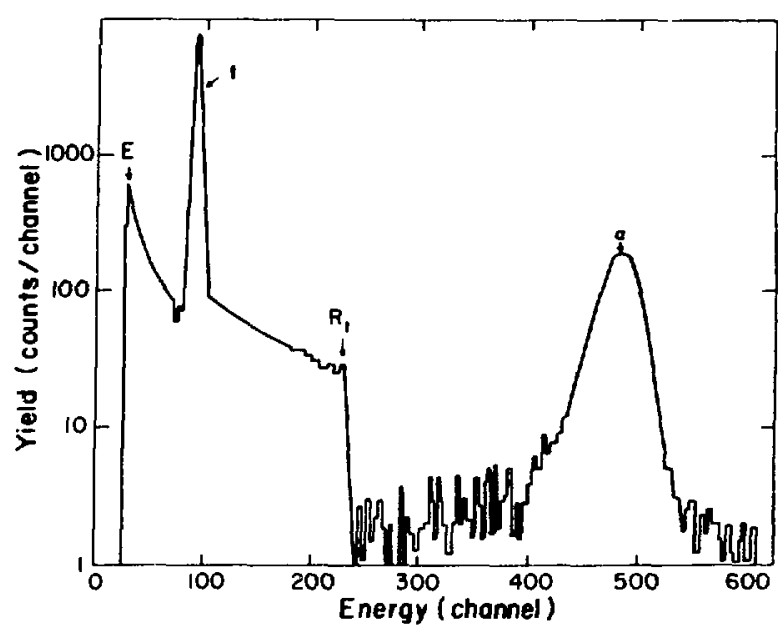

Fig. B-2

'He(t,a)'H singles spectrum at $8.980 \mathrm{MeV}, 30.00^{\circ}$ (lab angle). The alpha peak contains 10000 counts over a background of 200 counts.

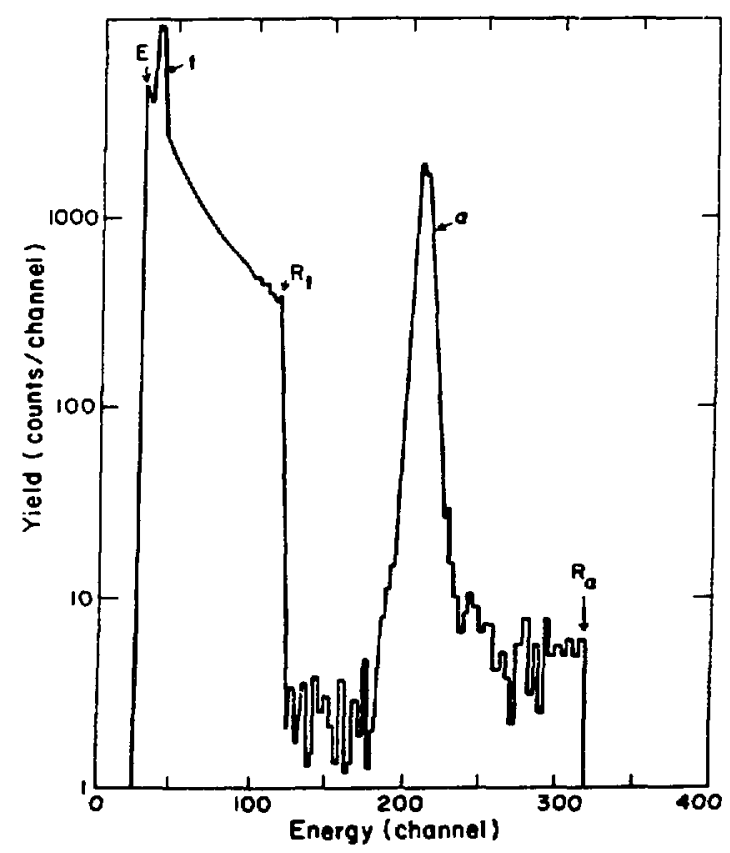

Fig. B-4

${ }^{4} \mathrm{He}(\mathrm{L}, \mathrm{a})^{3} \mathrm{H}$ singles spectrum at $12.000 \mathrm{MeV}, 20^{\circ}$ (lab angle). The alpha ,eak contains 22000 counts over a background of 340 counts. 
spectra. The error in the cross section caused by this correction was no more than $0.1 \%$. In some of the poorer alpha spectra, the background subtraction was as much as $3 \%$, contributing an error of $0.5 \%$ (Fig. B-3). In Fig. $B-1$, the peaks marked $C$ and $O$ are tritons scattered from contaminant carbon and oxygen. As discussed elsewhere, these peaks were used for gas purity estimation. Even at the smallest angles, the contaminant peaks were separable from the main peak. The edge " $E$ " denotes the cutoff resulting from an electronic window.

Figure B-2 shows a typical singles spectra from particles striking the front $C \mathrm{E}$ detector. Peaks caused by tritons and alphas are evident. Events in channels less than $R_{t}$ result from the large number of tritons passing through the detector; $R_{t}$ denotes the energy equivalent to the range of a triton in the $\mathbf{E}$ detector. The main alpha peak is marked " $\alpha$." In Fig. B-3, the bombarding energy and angle are such that the energy of recoil alphas almost corresponds to the rarge $\left(R_{\alpha}\right)$ of alpha particles in the detector. In Fig. B-4, the alphas pass through the detector with the spectrum folding back. The data in Fig. B-4 are still :seful but with increased uncertainty in the background subtraction.

Spectra were analyzed off-line to give cross sections with the accuracies cited. On-line analysis available during the experiment gave approximate cross sections to monitor the progress of the experiment. The cross sections were calculated from the yield and other measured parameters in a straightforward way. ${ }^{17}$ Corrections were negligible for reactions in the silicon detectors, rate pileup, beam heating of the target gas, multiple scattering compensation in the target exit foil, multiple scattering losses in the beam current collection, and second-order terms in the geometry factor G. ${ }^{16}$

Specific tests were made in several cases. Multiple scattering losses in the Faraday cup were tested by accurately measuring the yield at a given angle with and vithout an extra foil in the beam at the target exit.
Agreement was observed to $0.08 \% \pm 0.3 \%$ for triton beam energies of $7 \mathrm{MeV}$ and above.

To test for multiple scattering compensation, extra foils were placed over the target foil where the recuil particles exit. Negligible compensation error was found for alphas with energies greater than $4.2 \mathrm{MeV}$ and tritons with energies greater than $2.9 \mathrm{MeV}$. This includes all the particle energies of this experiment.

Significant contributions to the cross-section errors are shown in Table B-I. The larger error in the background and dead time was found in certain alpha spectra. Dead times were usually kept to $1 \%$ or less, with a negligible error. Errors in the data tables are quoted as scale and relative errors (standard deviations) where the scale error is defined so that the absolute error is the quadratic sum of the scale and relative error. In each case, the energy of the bombarding beam is known to $\pm 15 \mathrm{keV}$ with a FWHM spread of $40 \mathrm{keV}$, including the effects of foil thickness variation, foil and target-gas straggling, and machine energy resolution. The relative energy of adjacent runs in an excitation function is accurate to $\pm 5 \mathrm{keV}$. Data were taken successively left and right of the beam to decrease both the statistical error and certain mechanical asymmetries. For example, tests showed that the "indicated zero" of the detector arm angle was $0.16^{\circ}$ counterclockwise of true zero. The left-right run average avoided any correction caused by this zero shift. The total included angle of the detector slit system was $0.3^{\circ}$, and the final accuracy of the measured angle was $\pm 0.03^{\circ}$.

The resulting data were consistent in several ways. Besides the agreement between the singles and coincidence spectra already noted, agreement within the calculated error was observed for duplicated data points. The duplicated data points include angular distributions that were repeated after 9 months and overlap between the angular distributions and excitation functions where the energy and angle were duplicated.

TABLE B-I

Scale Relative

\begin{tabular}{|c|c|c|c|}
\hline \multicolumn{2}{|c|}{ Scale } & \multicolumn{2}{|c|}{ Relative } \\
\hline Source & $\%$ Error & Source & $\%$ Error \\
\hline Pressure & 0.1 & Yield & $100 / \sqrt{N}$ \\
\hline Temperature & 0.07 & Background & $0.1-0.5$ \\
\hline Purity & 0.2 & Dead time & $0.0-0.3$ \\
\hline Geometry & 0.2 & & \\
\hline Beam & 0.2 & & \\
\hline
\end{tabular}




\section{REFERENCES}

1. R. E. Brown, G. G. Ohlsen, R. F. Haglund, Jr., and Nelson Jarmie, ${ }^{63} \mathrm{H}\left(\alpha,{ }^{6} \mathrm{Li}\right)$ n Reaction at $0^{\circ}, "$ Phys. Rev. C. 16, 513 (1977).

2. R. D. Furber, "A Single-Channel Resonating Group Study of the Seven-Nucleon System Using a Noncentral Two-Nucleon Potential," Ph.D. Thesis, University of Minnesota, 1976. This material is also discussed by K. Wildermuth and Y. C. Tang in $A$ Unified Theory of the Nucleus (Academic Press, New York, 1977), Sec. 5.5, 7.3a, and 11.3a and in Ref. 22.

3. G. M. Hale, "R-Matrix Analysis of the 'Li System," in International Specialist Symposium on Neutron Standards and Applications, Gaithersburg (1977), NBS Special Publication 493, p. 30.

4. R. J. Spiger and T. A. Tombrello, "Scattering of $\mathrm{He}^{3}$ by $\mathrm{He}^{4}$ and of $\mathrm{He}^{4}$ by Tritium," Phys. Rev. 163, 964 (1967). This material is also discussed by R. J. Spiger in "Investigation of the Compound Nuclei ${ }^{7} \mathrm{Li}$ and 'Be," Ph.D. Thesis, California Institute of Technology, 1967.

5. R. A. Hardekopf, Nelson Jarmie, G. G. Ohlsen, R. V. Poore, R. F. Haglund, Jr., Ronald E. Brown, P. A. Schmelzbach, B. D. Anderson, D. M. Stupin, and P. A. Lovoi, " ${ }^{4} \mathrm{He}(\mathrm{t}, \mathrm{t})^{4} \mathrm{He}$ Elastic Scattering: Analyzing Powers and Differential Cross Sections," Los Alamos Scientific Laboratory report LA-6188 (January 1977).

6. R. A. Hardekopf, G. G. Ohlsen, R. V. Poore, and Nelson Jarmie, "Location of a Polarization Extremum in Triton-Alpha Scattering and its Application to a New Polarized Triton Source," Phys. Rev. C. 13, 2127 (1976). This material is also discussed by Nelson Jarmie, F. D. Correll, Ronald E. Brown, R. A. Hardekopf, and G. G. Ohisen in "Elastic Scattering of Polarized Tritons by "He," to be published in Polarization Phenomena in Nuclear Physics, Proc. AIP Conference, Santa Fe, N. Mex., August 11-15, 1980.

7. R. A. Hardekopf, "Operation of the LASL Polarized Triton Source," in Proceedings of the Fourth International Symposium on Polarization
Phenomena in Nuclear Reactions, W. Grüebler and V. König, Eds., Zürich, 1975 (Birkhäuser, Basel, 1976), p. 865.

8. P. A. Lovoi, "Proton-Proton Analyzing Power Measurements at $16 \mathrm{MeV}$," Los Alamos Scientific Laboratory report LA-5C41-T (September 1975). This material is also discussed by G. G. Ohisen and P. A. Lovoi in "The 'Supercube' Scattering Chamber for SPIN-1/2 and SPIN-1 Analyzing Power Measurements," in Proceedings of the Fourth International Symposium on Polarization Phenomena in Nuclear Reactions, W. Grüebler and V. König, Eds., Zurich, 1975 (Birkhäuser, Basel, 1976), p. 907.

9. F. F. Haglund, Jr., G. G. Ohlsen, R. A. Hardekopf, Nelson Jarmie, R. E. Brown, and P. A. Schmelzbach, " ${ }^{3} \mathrm{He}(\mathrm{t}, \mathrm{t})^{3} \mathrm{He}$ Elastic Scattering Measurements from 9 to $17 \mathrm{Mev,"} \mathrm{Phys.} \mathrm{Rev.} \mathrm{C.} 15$. 1613 (1977).

10. E. Huenges, H. Rösier, and H. Vonach, "High-Resolution Time-of-Flight System for Measurement of Excitation Energies and Q-Values," Phys. Lett. 46B, 361 (1973).

11. R. G. Clarkson and Nelson Jarmie, "Energy-loss Straggling of Heavy Charged Particles," Comput. Phys. Commun. 2, 433 (1971).

12. G. G. Ohlsen, J. L. McKibben, G. P. Lawrence, P. W. Keaton, Jr., and D. D. Armstrong, "Precise Proton-Polarization Standards Determined with a Lamb-Shift Ion Source Incorporating a Nuclear Spin Filter," Phys. Rev. Lett. 27, 599 (1971).

13. G. G. Ohlsen, and P. W. Keaton, Jr., "Techniques for Measurement of Spin-1/2 and Spin-1 Polarization Analyzing Tensors," Nucl. Instrum. Methods 109, 41 (1973).

14. G. G. Ohlsen, P. A. Lovoi, G. C. Salzman, U. Meyer-Berkhout, C. K. Mitchell, and W. Grüebler, "Analyzing Power for d- "He Elastic Scattering at 12.0, 14.0, and 17.0 MeV," Phys. Rev. C. 8, 1262 (1973). 
15. G. G. Ohlsen, P. A. Lovoi, R. A. Hardekopf, R. L. Walter, and P. W. Lisowski, "Depolarization Effects in Stripping a Polarized Negative Ion Beam," Nucl. Instrum. Methods 131, 489 (1975).

16. E. A. Silverstein, "Calculation of the G Factor For Gas Scattering Experiments," Nucl. Instrum. Methods 4, 53 (1959).

17. Nelson Jarmie, J. H. Jett, J. L. Detch, Jr., and R. L. Hutson, "Proton-Proton Elastic Scattering From 9.6 to $13.6 \mathrm{MeV}$," Phys. Rev. C. 3, 10 (1971). This material is also discussed by J. L. Detch, Jr., in collaboration with R. L. Hutson, Nelson Jarmie and J. H. Jett in "Accurate Cross Section Measurements of the Reaction $T(p, p) T, T(p, d) D, T\left(p,{ }^{3} \mathrm{He}\right) \mathrm{N}$, and $\mathrm{T}(\overrightarrow{\mathrm{p}}, \hat{\mathrm{p}}) \mathrm{T}$ at $13.600 \mathrm{MeV}, "$ Los Alamos Scientific Laboratory report LA-4576-T (February, 1971).

18. C. T. Chase and R. T. Cox, "The Scattering of 50-Kilovolt Electrons by Aluminum," Phys. Rev. 58,243 (1940).
19. F. Ajzenberg-Selove, "Energy Levels of Light Nuclei: $A=5-10$," Nucl. Phys. A230, 56 (1979).

20. R. A. Hardekopf, W. Grüebler, B. Jenny, V. König, R. Risler, H. R. Bürgi, and J. Nurzynski, "Investigation of the $1^{+}$Resonance in " $\mathrm{Li}$ by d-a Scattering Between 6 and $7 \mathrm{MeV}$," Nucl. Phys. A287, 237 (1977).

21. F. James and M. Roos, "Minut-A System for Functions Minimization and Analysis of the Parameter Errors and Correlations," Comp. Phys. Comm. 10,343 (1975).

22. R. E. Brown, "Light Nuclei: An Experimental Proving Ground for the Microscopic Cluster Model," in Clustering Aspects of Nuclear Structure and Nuclear Reactions, W. T. H. van Oers et al., Eds., Winnipeg, Manitoba, 1978 (American Institute of Physics, New York, 1978), p. 90. 